\title{
Transient Analysis of an FHR Coupled to a Helium Brayton Power Cycle
}

\author{
Minghui Chen ${ }^{\mathrm{a}}$, In Hun Kim ${ }^{\mathrm{a}}$, Xiaodong Sun ${ }^{\mathrm{a},{ }^{*}}$, Richard Christensen ${ }^{\mathrm{a}}$, Vivek Utgikar ${ }^{\mathrm{b}}$, Piyush Sabharwall ${ }^{\mathrm{c}}$ \\ ${ }^{a}$ : Nuclear Engineering Program, The Ohio State University, Columbus, OH 43210 \\ ${ }^{b}$ : University of Idaho, Idaho Falls, ID 83401 \\ ${ }^{c}$ : Idaho National Laboratory, Idaho Falls, ID 83415 \\ *Email: $\underline{\text { sun.200@osu.edu }}$
}

\begin{abstract}
The Fluoride salt-cooled High-temperature Reactor (FHR) combines the coated particle fuel and graphite moderator with a liquid fluoride salt as the coolant. It features a passive decay heat removal system and a high-efficiency Brayton cycle for electricity generation. It typically employs an intermediate loop, consisting of an intermediate heat exchanger (IHX) and a secondary heat exchanger (SHX), to couple the primary system with the power conversion unit (PCU). In this study, a preliminary dynamic system model is developed to simulate transient characteristics of a prototypic $20-\mathrm{MW}_{\text {th }}$ Fluoride salt-cooled High-temperature Test Reactor (FHTR). The model consists of a series of differential conservation equations that can be numerically solved using the MATLAB platform. For the reactor, a point neutron kinetics model is adopted. For the IHX and SHX, a fluted tube heat exchanger and an offset strip-fin heat exchanger are selected, respectively. Detailed geometric designs of each component in the FHTR are determined based on the FHTR nominal steady-state operating conditions. Three initiating events are simulated in this study, including a positive reactivity insertion, a step increase in the mass flow rate of the PCU helium flow, and a step increase in the PCU helium inlet temperature to the SHX. The simulation results show that the reactor has inherent safety features for those three simulated scenarios. It is observed that the increase in the temperatures of the fuel pebbles and primary coolant is mitigated by the decrease in the reactor power due to negative temperature feedbacks. The results also indicate that the intermediate loop with the two heat exchangers plays a significant role in the transient progression of the integral reactor system.
\end{abstract}

Key words: FHR; Transient Thermal-hydraulic Analysis; Intermediate Heat Exchanger (IHX); Secondary Heat Exchanger (SHX); Modeling and Simulation. 


\section{Introduction}

The Fluoride salt-cooled High-temperature Reactors (FHRs) combine the coated particle fuel and graphite moderator with a liquid fluoride salt as the coolant for electricity generation and process heat applications. Fluoride salts were studied extensively for the Molten Salt Reactors (MSRs) from 1950s to 1970s [1], while only recently have these salts been considered to be used in the solidfuel high-temperature reactors, namely, FHRs. The high volumetric heat capacity of these fluoride salts provides potential for a higher power density than the gas-cooled reactors and enables a compact reactor system. In addition, the FHR is designed to employ a fully passive decay heat removal system and a high-efficiency Brayton power cycle [2-3].

Figure 1 shows a schematic of an FHR that is coupled to a helium Brayton cycle system through an intermediate loop. In this FHR design, it adopts a cylindrical core with uniformly distributed fuel pebbles. In the literature, an annular core is also proposed due to its lower peaking power [4]. The intermediate loop draws on an intermediate heat exchanger (IHX) and a secondary heat exchanger (SHX) to link the primary system with the power conversion unit (PCU). The working fluids used in the reactor primary loop and intermediate loop are FLiBe and FLiNaK, respectively.

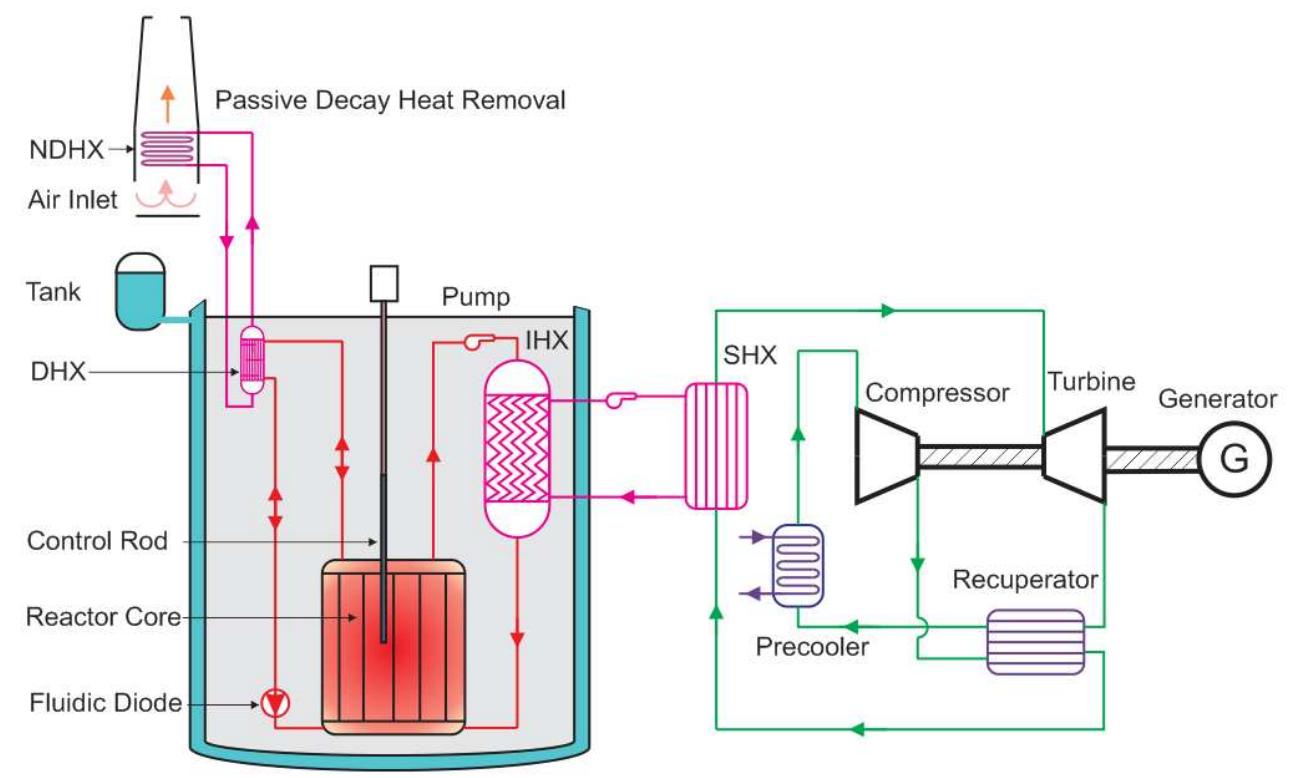

Figure 1. Schematic of an FHR coupled to a helium turbine system through an intermediate loop

Direct reactor auxiliary cooling system (DRACS) is a passive heat removal system that has been proposed for FHRs [2-3]. The DRACS has two sets of heat exchangers, namely, DRACS heat exchanger (DHX) and natural draft heat exchanger (NDHX), as shown in Figure 1. The DHX is submerged in the primary coolant inside the reactor vessel and the NDHX is placed inside the air chimney. The DRACS consists of three coupled natural circulation (natural convection) loops relying completely on buoyancy as the driving 
force. The primary salt flow into the DRACS is restricted under reactor normal operations by means of a fluidic diode, which has large flow resistance in its reverse flow direction, i.e., the upward direction as shown in Figure 1. As a result, only a small amount of the salt flow goes into the DRACS to prevent the DRACS secondary salt from overcooling and ensure that the DRACS can function promptly after reactor shutdown. The PCU is a closed-loop helium Brayton cycle that could provide a higher power conversion efficiency compared to the steam Rankine cycle. Another potential power cycle option is the nuclear air-Brayton combined cycle because of its mature technology and capability of producing peak power [2]. The projected thermal efficiency of the FHR plant that coupled to a nuclear air-Brayton combined cycle is up to $47 \%$ [2]. It should be noted that one of the Fluoride salt-cooled High-temperature Test Reactor (FHTR) design requirements is to deliver thermal power to a variety of applications, such as process heat for hydrogen generation and refineries. In that configuration, the process heat application plants are also coupled to the primary reactor system. Therefore, in modeling the behavior of an FHR integral system, it becomes essential to consider the primary reactor system, DRACS, intermediate loop, PCU, and process heat application plant. In our current study, the DRACS and process heat application plant are however not considered.

Understanding dynamic behaviors is of great importance in designing FHR power plants. The intermediate loop plays an important role in the dynamic behavior evolution of the integral system because any transient or accident either in the primary loop or PCU could propagate to the other side via the intermediate loop. Galvez [5] designed an air-cooled passive safety system and performed a loss of forced cooling with scram event for the Pebble Bed Advanced High-Temperature Reactor (PB-AHTR). In the literature, little information is available on the transient behaviors of the FHRs coupled to a power conversion system, particularly under abnormal conditions.

As for tools that used to perform simulations, although many existing codes are available, none of them is selected. The available thermal hydraulics codes, such as TRACE and THERMIX, do not have fluoride salt properties and comprehensive heat exchanger models built in. Though the properties of fluoride salts have been included in RELAP5-3D, it is difficult to add new detailed components, such as fluted tube heat exchanger and offset strip-fin heat exchanger, to the existing code. The main objective of this study is to develop a simplified tool that can simulate the FHTR transient response to various initiating events. A preliminary dynamic system model is developed in current work to simulate transient characteristics of a prototypic 20-MWth FHTR, consisting two identical PCU loops. The model consists of a series of differential conservation equations that can be numerically solved using the MATLAB platform. For the reactor, a point neutron kinetics model is adopted. For the IHX and SHX, a fluted tube heat exchanger and an offset strip-fin heat exchanger are selected, respectively. Detailed geometric designs of each component in the FHTR are determined based on the FHTR plant nominal steady-state operating conditions. Three initiating events are simulated in this study, 
including a positive reactivity insertion, a step increase in the mass flow rate of the PCU helium flow, and a step increase in the PCU helium inlet temperature to the SHX.

\section{Modeling}

\subsection{Reactor Core Models}

The FHTR has a cylindrical core with uniformly distributed pebble fuel. During the reactor normal operation, the primary coolant is assumed to flow from the core bottom to the top with a temperature rise from 600 to $704^{\circ} \mathrm{C}$ through the reactor core. A simplified one-dimensional model is adopted to simulate the entire core, which is axially divided into several segments with a prescribed power distribution. It is assumed that the reactor is under perfect thermal insulation and that the heat loss to the surroundings is therefore neglected. The entire fuel is considered as a whole and hence the pebble fuel only transfers heat to the coolant by forced convection while the heat transfer between the fuel pebbles and from the pebbles to the coolant by radiation is neglected. The radial temperature distribution at each elevation in the core would be flattened during a small time interval. Also, the heat conduction from the core to the peripheral structural materials during a transient is neglected. Therefore, the heat conduction in the radial direction is not considered. These assumptions are considered reasonable because the heat transfer from the pebble fuel to the coolant is dominated by forced convection. In addition, these are conservative assumptions, so the results that obtained from the simplified calculations would give an underestimation of the heat transfer capacity of the coolant.

For energy conservation in the pebble fuel,

$$
\begin{aligned}
\rho_{p b} c_{p, p b} \frac{\partial T_{p b}(z, t)}{\partial t} & =\frac{\partial}{\partial z}\left[k_{p b}(z, t) \frac{\partial T_{p b}(z, t)}{\partial z}\right]+\dot{q}_{n}^{\prime \prime \prime}(z, t) \\
\dot{q}_{c}(z, t) & =h_{f} A_{R}\left[T_{p b}(z, t)-T_{f}(z, t)\right]
\end{aligned}
$$

where $T_{p b}$ is the pebble fuel temperature $\left[{ }^{\circ} \mathrm{C}\right] ; T_{f}$ is the primary coolant temperature $\left[{ }^{\circ} \mathrm{C}\right] ; \rho_{p b} c_{p, p b}$ is the volumetric heat capacity of the pebbles $\left[\mathrm{J} /\left(\mathrm{m}^{3}-{ }^{\circ} \mathrm{C}\right)\right] ; \quad k_{p b}$ is the pebble thermal conductivity $\left[\mathrm{W} /\left(\mathrm{m}-{ }^{\circ} \mathrm{C}\right)\right] ; \quad \dot{q}_{n}{ }^{\prime \prime} \quad$ is the internal energy generation rate density due to fission $\left[\mathrm{W} / \mathrm{m}^{3}\right] ; \quad \dot{q}_{c}$ is the heat transfer rate via convection $[\mathrm{W}] ; h_{f}$ is the heat transfer coefficient between the pebbles and primary coolant $\left[\mathrm{W} /\left(\mathrm{m}^{2}{ }^{\circ} \mathrm{C}\right)\right]$; and $A_{R}$ is total heat transfer area in one computational segment in the reactor core $\left[\mathrm{m}^{2}\right]$. The subscripts $p b$ and $f$ denote the pebble fuel and primary coolant, respectively.

For energy conservation in the primary coolant, 


$$
m_{f} c_{p, f} \frac{\partial T_{f}(z, t)}{\partial t}+\dot{m}_{f} c_{p, f}\left[T_{f}^{o u t}(z, t)-T_{f}^{\text {in }}(z, t)\right]=\dot{q}_{c}(z, t)
$$

where $m_{f}$ is the coolant mass in one computational node $[\mathrm{kg}] ; c_{p, f}$ is the coolant specific heat $\left[\mathrm{J} /\left(\mathrm{kg}-{ }^{\circ} \mathrm{C}\right)\right] ;$ and $\dot{m}_{f}$ is the coolant mass flow rate $[\mathrm{kg} / \mathrm{s}]$.

For fluoride salt flow into the pebble bed, the Wakao correlation [5-6] is used to calculate the Nusselt number as:

$$
\mathrm{Nu}=2+1.1 \operatorname{Re}^{0.62} \operatorname{Pr}^{0.33}
$$

where $\mathrm{Nu}$, Re, and $\operatorname{Pr}$ are the Nusselt number, Reynolds number, and Prandtl number, respectively. This correlation is applicable for $15<\operatorname{Re}<8500$.

The pressure drop across the pebble bed can be obtained by using the Ergun equation [4]:

$$
\Delta p=\frac{1-\varepsilon}{\varepsilon^{3}}\left(170 \frac{\mu A_{c}}{\dot{m}_{f} d_{p}}(1-\varepsilon)+1.75\right) \frac{L}{d_{p} \rho}\left(\frac{\dot{m}_{f}}{A_{c}}\right)^{2},
$$

where, $\varepsilon, \mu, \rho$ and $\dot{m}_{f}$ are the volume fraction, dynamic viscosity, density, and mass flow rate of the primary coolant, respectively, while $L, A_{c}$, and $d_{p}$ denote the height of active region of the reactor core, the cross-sectional area of the reactor core, and the pebble outer diameter, respectively.

The negative reactivity feedback to the reactor core caused by the fuel temperature is modeled using the one-group point kinetic equation as [7-8]:

$$
\begin{gathered}
\frac{\mathrm{d} n(t)}{\mathrm{d} t}=\frac{[R(t)-\beta]}{\Lambda} n(t)+\lambda C \\
\frac{\mathrm{d} C}{\mathrm{~d} t}=\left(\frac{\beta}{\Lambda}\right) n(t)-\lambda C
\end{gathered}
$$

where $n$ is the neutron density $\left[\mathrm{n} / \mathrm{m}^{3}\right] ; C$ is the concentration of neutron precursor; $\beta$ is the delayed neutron fraction; $\lambda$ is the decay constant $\left[\mathrm{s}^{-1}\right]$; and $\Lambda$ is the mean neutron generation time [s]. The total fission power of the reactor can be calculated from the neutron density.

The fuel Doppler effect and primary coolant temperature feedback are considered in this model [8]. Neutron poisons that provide long-time burn-up reactivity control are neglected at this point. The total reactivity can be expressed as: 


$$
R(t)=R_{0}+R_{C R}+F_{p b}\left[\bar{T}_{p b}(t)-\bar{T}_{p b}(0)\right]+F_{f}\left[\bar{T}_{f}(t)-\bar{T}_{f}(0)\right]
$$

where $R_{0}$ is the initial reactivity; $R_{C R}$ is the control rod reactivity; $F$ is the negative feedback coefficient; $\bar{T}$ is the mass weighted temperature in the core $\left[{ }^{\circ} \mathrm{C}\right]$, and $\bar{T}(0)$ is the reference temperature $\left[{ }^{\circ} \mathrm{C}\right]$.

\subsection{IHX Model}

Fluted tube heat exchanger (FTHX), a shell-and-tube type heat exchanger, is selected as the IHX type due to its favorable heat transfer enhancement with good pressure drop characteristics. Instead of using plain tubes, FTHX uses spirally fluted tubes to induce swirling flow to increase the heat transfer rate. It also adopts a baffle-free design to reduce the vibration and fouling inside the heat exchanger. Figures 2.a and 2.b show a side-view image and a cross-section schematic of a four-start spirally fluted tube, respectively. The swirling flow pattern on the shell and tube sides leaves no stagnant areas where the surface is vulnerable to fouling. This flow pattern would also help reduce the pressure drop and enhance the heat transfer in the heat exchanger. In the baffle-free design, each tube is firmly and frequently supported by its adjacent flutes. This design is protected against flow-induced vibrations [9]. Since fouling could be a serious issue in FHRs due to the potentially highly corrosive fluoride salts under high temperatures, FTHX is therefore proposed as the IHX for FHRs.

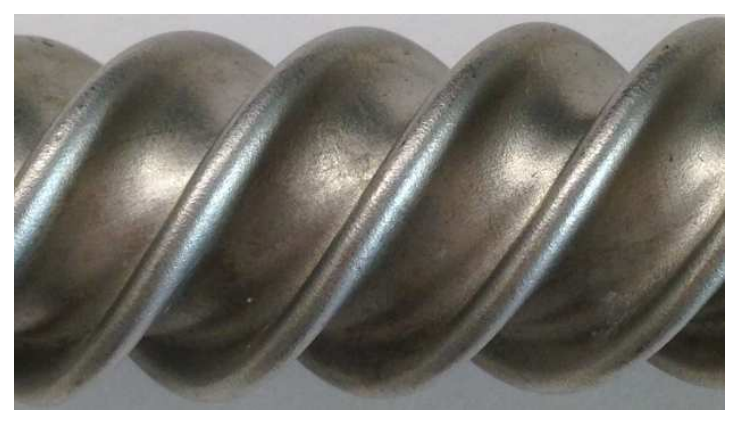

(a) Side-view image

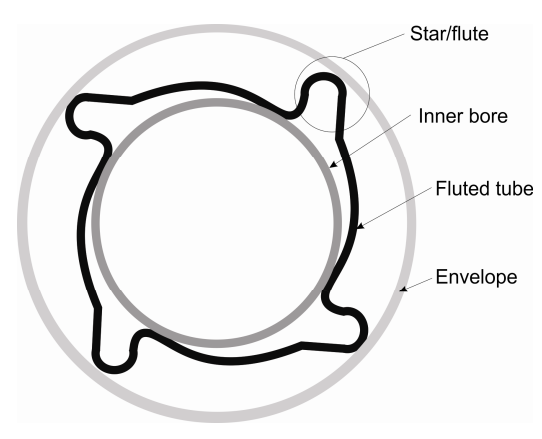

(b) Cross-section schematic

Figure 2. A four-start spirally fluted tube

Extensive thermal hydraulic investigations of the FTHX have been conducted by Christensen and Garimella [10-12]. The IHX operates under a FLiBe-to-FLiNaK environment with the primary salt FLiBe on the tube side and FLiNaK on the shell side. The detailed design parameters of the IHX can be obtained by following a design procedure developed by Garimella [12]. The correlations that were used in this study are listed in the following.

For the shell side: 


$$
\mathrm{Nu}=\left[\frac{\left(f_{f} / 8\right) \operatorname{Re} \operatorname{Pr}}{1+9.77 \sqrt{f_{f} / 8}\left(\operatorname{Pr}^{2 / 3}-1\right)}\right]\left(\operatorname{Re}^{-0.20} e^{*-0.32} p^{*-0.28} r^{*-1.64}\right)
$$

where the friction factor $f_{f}$ is given as:

$$
f_{f}=\frac{96 r^{* 0.035}}{\operatorname{Re}}\left(1+101.7 \operatorname{Re}^{0.52} e^{* 1.65+2.00 \theta^{*}} r^{*-5.77}\right)
$$

For the tube side:

$$
\mathrm{Nu}=0.014 \operatorname{Re}^{0.842} e^{*-0.067} p^{*-0.293} \theta^{*-0.705} \operatorname{Pr}^{0.4}
$$

where, $e^{*}$ and $p^{*}$ are the dimensionless flute depth and pitch obtained by using the volume-based fluted tube inner diameter, respectively. $\theta^{*}$ is the non-dimensional helix angle with respect to $90^{\circ}$ and $r^{*}$ is the ratio of the volume-based fluted tube outer diameter to the shell inner diameter. From the chart that was presented by Garimella [12], these correlations are validated for $300<\operatorname{Re}<800$. The Reynolds number is calculated as:

$$
\operatorname{Re}=\frac{\rho v D_{\mathrm{FTHX}}}{\mu}
$$

where, $\rho, \mu$ and $v$ denote the fluid density, fluid dynamic viscosity and flow velocity. The hydraulic diameter $D_{\text {FTHх }}$ is given by:

$$
D_{\text {FTHX }}=D_{o}-D_{v o}
$$

where, $D_{o}$ and $D_{v o}$ are the inner diameter of the outer plain tube and the volume-based fluted tube outer diameter, respectively.

The dynamic model to evaluate the performance of the FTHX-type IHX design was developed based on the energy balance equations of two-stream countercurrent heat exchanger with the following assumptions: i. The heat loss in the piping systems was assumed negligible; ii. The heat conductions in the fluted tubes and working fluids in the flow directions were assumed negligible; iii. Heat loss to the surroundings via the heat exchanger shell was neglected; iv. Constant specific heat was used; and v. The heat conduction resistance due to the wall could be neglected because of the thin wall and large thermal conductivity of the wall material.

Based on the aforementioned assumptions, by integrating the energy balance equations over the IHX, we obtained the following equations for the transient analysis code:

For the tube-side fluid: 


$$
m_{t} c_{p, t} \frac{\mathrm{d} T_{t}}{\mathrm{~d} t}+\dot{m}_{t} c_{p, t}\left(T_{t}^{o u t}-T_{t}^{i n}\right)=(h A)_{t}\left(T_{W}-T_{t}\right)
$$

For the shell-side fluid:

$$
m_{s} c_{p, s} \frac{\mathrm{d} T_{s}}{\mathrm{~d} t}+\dot{m}_{s} c_{p, s}\left(T_{s}^{o u t}-T_{s}^{i n}\right)=(h A)_{s}\left(T_{W}-T_{s}\right)
$$

For the tube wall:

$$
m_{W} c_{p, W} \frac{\mathrm{d} T_{W}}{\mathrm{~d} t}=(h A)_{t}\left(T_{t}-T_{W}\right)-(h A)_{s}\left(T_{W}-T_{s}\right)
$$

Here, the subscripts $t, s$, and $W$ denote the IHX tube-side fluid, shell-side fluid, and tube wall, respectively. $A$ is the total heat transfer area in one segment of the IHX. The superscripts in and out denote the inlet and outlet temperatures for a specific mesh volume.

\subsection{SHX Model}

Offset strip-fin heat exchanger (OSF) is selected as the SHX type in this system dynamic model. OSF is a plate-type heat exchanger with flow channels chemically etched on the plates and then plates diffusion bonded to form the heat exchanger core. Flow channels with offset-strip fins help interrupt the flow from becoming fully developed and thereby restarting the boundary layers, which can significantly increase the heat transfer coefficient [13-15]. Figure 3 shows a schematic of one geometric unit cell, illustrating the offset strip-fin concept [14-15].

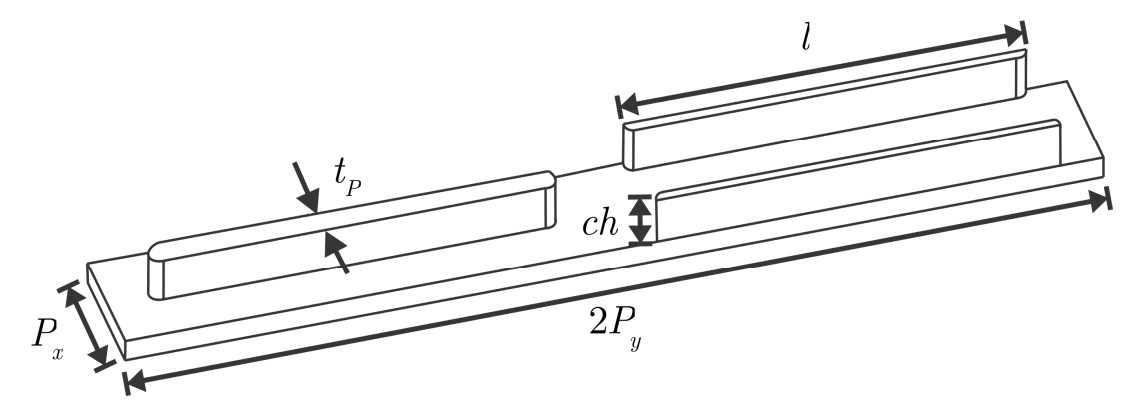

Figure 3. One geometric unit cell of the plate with the offset strip fins

The SHX operates under a FLiNaK-to-helium condition. FLiNaK is on the hot side and helium is on the cold side. Correlations have been developed in the literature to evaluate the heat transfer coefficient of offset strip-fin heat exchangers. The correlation 
showed in Eq. (17) is for calculating the Colburn factor, $j$, developed by Manglik and Bergels [16] for the offset strip-fin heat exchangers is considered in this study.

$$
j=0.6522 \operatorname{Re}^{-0.5403} \chi^{-0.1541} \delta^{0.1499} \gamma^{-0.0678}\left(1+5.269 \times 10^{-5} \operatorname{Re}^{1.34} \chi^{0.504} \delta^{0.456} \gamma^{-1.055}\right)^{0.1}
$$

where $\chi=\left(P_{x}-t_{P}\right) /$ ch, $\delta=t_{P} / l$ and $\gamma=t_{P} /\left(P_{x}-t_{P}\right)$. As shown in Figure 3, ch is the fin height $[\mathrm{m}]$; $t_{P}$ is the fin thickness [m]; $P_{x}$ and $P_{y}$ are the pitch in the span-wise direction and stream-wise direction, respectively [m]; and $l$ is the fin length [m]. This correlation is valid for $120<\operatorname{Re}<10^{4}$ and $0.5<\operatorname{Pr}<15$. The heat transfer coefficient $h$ can be obtained from the Colburn factor as:

$$
h=\frac{\mathrm{Nu} k_{f}}{D_{\mathrm{OSF}}}=j\left(\operatorname{Re} \operatorname{Pr}^{1 / 3}\right) \frac{k_{f}}{D_{\mathrm{OSF}}},
$$

where, $k_{f}$ is the thermal conductivity of the fluid $\left[\mathrm{W} /\left(\mathrm{m}-{ }^{\circ} \mathrm{C}\right)\right]$ and $D_{\mathrm{OSF}}$ is the channel hydraulic diameter of the OSF $[\mathrm{m}]$.

A dynamic model of the SHX is obtained by using the same method that was proposed for the IHX. The SHX is considered as a two-stream countercurrent heat exchanger as well. In order to account for the complex fin geometry inside the heat exchanger, a parameter called surface area density is introduced in the dynamic model [15]. The energy balance equations for the fluids and plate can be written as follows:

For the hot-side fluid:

$$
\rho_{h} c_{p, h} \frac{\mathrm{d} T_{h}}{\mathrm{~d} t}+\frac{\rho_{h} c_{p, h} u_{h}}{x}\left(T_{h}^{\text {out }}-T_{h}^{i n}\right)=(h \alpha)_{h}\left(T_{P}-T_{h}\right)
$$

For the cold-side fluid:

$$
\rho_{c} c_{p, c} \frac{\mathrm{d} T_{c}}{\mathrm{~d} t}+\frac{\rho_{c} c_{p, c} u_{c}}{x}\left(T_{c}^{o u t}-T_{c}^{i n}\right)=(h \alpha)_{c}\left(T_{P}-T_{c}\right)
$$

For the solid plate:

$$
\rho_{P} c_{p, P} \frac{\mathrm{d} T_{P}}{\mathrm{~d} t}=(h \alpha)_{h}\left(T_{h}-T_{P}\right)-(h \alpha)_{c}\left(T_{P}-T_{c}\right)
$$


Here, the subscripts $h, c$, and $P$ denote the hot-side fluid, cold-side fluid and plates of the SHX, respectively; $\alpha$ is the surface area density $\left[\mathrm{m}^{2} / \mathrm{m}^{3}\right] ; x$ is the flow length for an individual mesh volume $[\mathrm{m}]$; and $u$ is the flow velocity [m/s]. As for the effect of the fins, the heat conduction resistance due to the fins could be neglected, as noted earlier, because of the small fin thickness and relatively large thermal conductivity of the plate/fin material. Therefore, the fin efficiency $\eta_{f}$ becomes a function of the convective heat transfer coefficient [15], defined as:

$$
\eta_{f}=\frac{\tanh \left(\phi \frac{c h}{2}\right)}{\left(\phi \frac{c h}{2}\right)}, \phi \approx\left(\frac{2 h}{k_{P} t_{P}}\right)^{\frac{1}{2}}
$$

where $k_{P}$ is the thermal conductivity of the plate material $\left[\mathrm{W} /\left(\mathrm{m}-{ }^{\circ} \mathrm{C}\right)\right]$. Then, the surface area density $\alpha$ can be expressed as:

$$
\alpha=\frac{A_{P}+\eta_{f} A_{f}}{V}
$$

where $A_{P}$ and $A_{f}$ are the plate and fin surface areas that are in contact with the surrounding fluid [m $\left.{ }^{2}\right]$, respectively; and $V$ is the volume of one unit cell $\left[\mathrm{m}^{3}\right]$

\section{Results and Discussion}

\subsection{Steady-State Operation}

To predict the dynamic behaviors of the FHTR, steady-state operation parameters are calculated first by assuming constant fluid properties. The design parameters of the FHTR are summarized in Table 1. The active core height and radius are obtained from one of the FHTR reference designs [2]. The required pumping power over the core is about $393.2 \mathrm{~W}$, which can be neglected compared with the total reactor thermal power. The primary coolant temperature profile from the bottom to the top along the axial direction in the reactor core is obtained by dividing the core into 50 segments, as shown in Figure 4. 
Table 1. Reactor core steady-state operating parameters [2]

\begin{tabular}{|l|c|c|}
\hline Parameter & Unit & Value \\
\hline Total thermal power & MW & 20 \\
\hline Primary coolant inlet temperature & ${ }^{\circ} \mathrm{C}$ & 600 \\
\hline Primary coolant outlet temperature & ${ }^{\circ} \mathrm{C}$ & 704 \\
\hline Primary nominal mass flow rate & $\mathrm{kg} / \mathrm{s}$ & 80.6 \\
\hline Fuel pebble diameter & $\mathrm{mm}$ & 30 \\
\hline Bed packing fraction & - & 0.61 \\
\hline Active core height & $\mathrm{m}$ & 1.52 \\
\hline Active core radius & - & 0.43 \\
\hline Reynolds number & $\mathrm{mPa}$ & 600 \\
\hline Pressure drop across the reactor core & $\mathrm{W}$ & 393.2 \\
\hline Pumping power over the reactor core & $\mathrm{W} /\left(\mathrm{m}^{2}-{ }^{\circ} \mathrm{C}\right)$ & 9309 \\
\hline Convective heat transfer coefficient in the core & & 9.57 \\
\hline
\end{tabular}

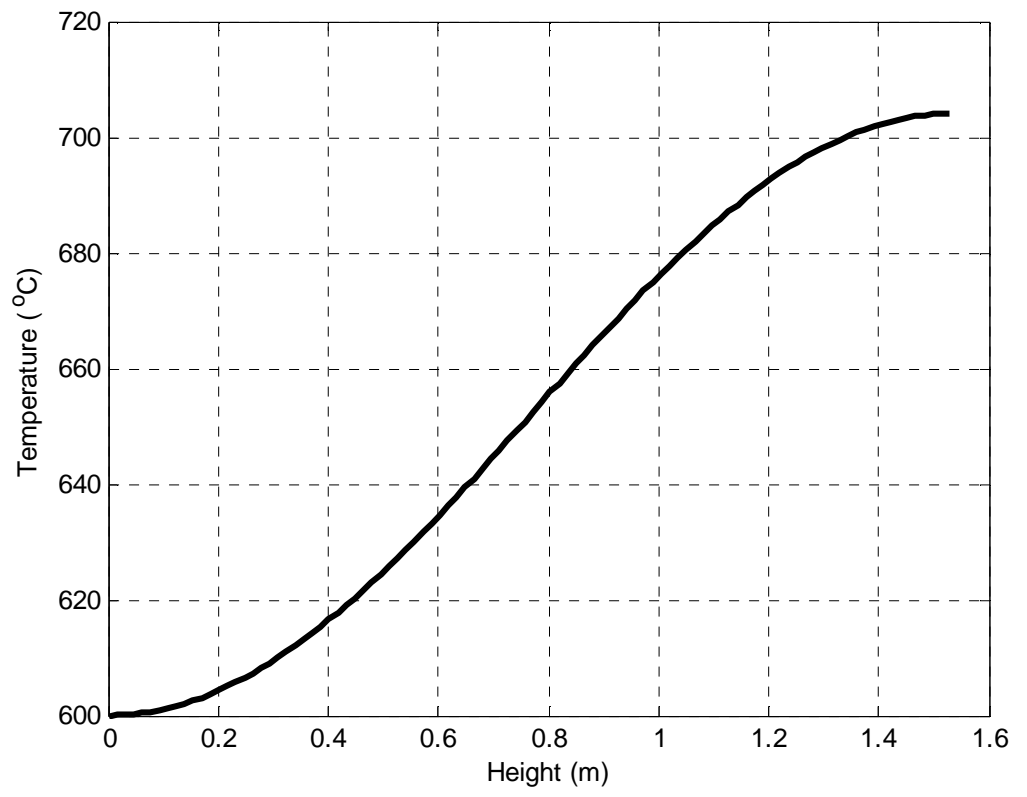

Figure 4 . The coolant temperature profile along the axial direction in the core 
Table 2. Steady-state operation conditions of the IHX and SHX [17]

\begin{tabular}{|l|c|c|c|}
\hline Parameter & Unit & IHX Value & SHX Value \\
\hline Nominal thermal duty & MWth & \multicolumn{2}{|c|}{10} \\
\hline Hot-side inlet temperature & ${ }^{\circ} \mathrm{C}$ & 704 & 690 \\
\hline Hot-side outlet temperature & ${ }^{\circ} \mathrm{C}$ & 600 & 545 \\
\hline Cold-side inlet temperature & ${ }^{\circ} \mathrm{C}$ & 545 & 498.9 \\
\hline Cold-side outlet temperature & ${ }^{\circ} \mathrm{C}$ & 690 & 651.2 \\
\hline
\end{tabular}

Preliminary thermal designs of both the IHX and SHX were carried out by using the Log-Mean Temperature Difference (LMTD) method. The operation conditions of the IHX and SHX are shown in Table 2 [17]. Each PCU loop is designed for a nominal thermal power of $10 \mathrm{MW}$. Both the IHX and SHX have a nominal thermal duty equal to the PCU power. It should be noted that these heat exchanger designs are not necessarily optimized.

Table 3 summarizes the IHX steady-state design parameters under plant normal operation. The fluted tube geometry is chosen in such a way that these fluted tubes can actually be fabricated by a commercial vendor. The heat transfer coefficient of the shell side is much larger than that of the tube side due to the baffle-free design and relative large fluted tube diameter. Smaller tubes are not considered at this point due to the potential fouling caused by the potentially corrosive fluoride salt. The overall power density of the IHX is approximately $3 \mathrm{MW} / \mathrm{m}^{3}$. 
Table 3. IHX steady-state design parameters

\begin{tabular}{|c|c|c|}
\hline Parameter & Unit & Value \\
\hline Fluted tube inner bore diameter & $\mathrm{mm}$ & 9.3 \\
\hline Fluted tube outside envelope diameter & $\mathrm{mm}$ & 16.2 \\
\hline Fluted tube wall thickness & $\mathrm{mm}$ & 1 \\
\hline Flute pitch & $\mathrm{mm}$ & 6.6 \\
\hline Number of fluted starts & - & 4 \\
\hline Nominal shell diameter & $\mathrm{m}$ & 0.838 \\
\hline Total number of fluted tubes & - & 2332 \\
\hline Total heat transfer area (O.D.) & $\mathrm{m}^{2}$ & 471 \\
\hline Tube-side Reynolds number & - & 317 \\
\hline Shell-side Reynolds number & - & 395 \\
\hline Tube-side fluid velocity & $\mathrm{m} / \mathrm{s}$ & 0.11 \\
\hline Shell-side fluid velocity & $\mathrm{m} / \mathrm{s}$ & 0.056 \\
\hline Tube-side heat transfer coefficient & $\mathrm{W} /\left(\mathrm{m}^{2}-{ }^{\circ} \mathrm{C}\right)$ & 992 \\
\hline Shell-side heat transfer coefficient & $\mathrm{W} /\left(\mathrm{m}^{2}-{ }^{\circ} \mathrm{C}\right)$ & 3541 \\
\hline Overall heat transfer coefficient & $\mathrm{W} /\left(\mathrm{m}^{2}-{ }^{\circ} \mathrm{C}\right)$ & 707 \\
\hline Tube length & $\mathrm{m}$ & 5.7 \\
\hline Pressure drop on the tube side & $\mathrm{kPa}$ & 2.5 \\
\hline Pressure drop on the shell side & $\mathrm{kPa}$ & 6.5 \\
\hline Total heat exchanger volume & $\mathrm{m}^{3}$ & 3.1 \\
\hline
\end{tabular}

Table 4 summarizes the SHX steady-state design parameters under plant normal operation. It can be seen that the cold side (i.e., the helium side) hydraulic diameter is about twice that of the hot side (i.e., FLiNaK side) and the cold side has a lower heat transfer coefficient than the hot side. The overall power density of the proposed SHX design is approximately $34 \mathrm{MW} / \mathrm{m}^{3}$. 
Table 4. SHX steady-state design parameters

\begin{tabular}{|c|c|c|}
\hline Parameter & Unit & Value \\
\hline Hot-side hydraulic diameter & $\mathrm{mm}$ & 1.2 \\
\hline Cold-side hydraulic diameter & $\mathrm{mm}$ & 2.2 \\
\hline Plate width & $\mathrm{m}$ & 0.6 \\
\hline Hot-side Reynolds number & - & 149 \\
\hline Cold-side Reynolds number & - & 4433 \\
\hline Hot-side fluid velocity & $\mathrm{m} / \mathrm{s}$ & 0.26 \\
\hline Cold-side fluid velocity & $\mathrm{m} / \mathrm{s}$ & 18.6 \\
\hline Hot-side Nusselt number & - & 9 \\
\hline Cold-side Nusselt number & - & 22 \\
\hline Hot-side heat transfer coefficient & $\mathrm{W} /\left(\mathrm{m}^{2}-{ }^{\circ} \mathrm{C}\right)$ & 6776 \\
\hline Cold-side heat transfer coefficient & $\mathrm{W} /\left(\mathrm{m}^{2}-{ }^{\circ} \mathrm{C}\right)$ & 3217 \\
\hline $\begin{array}{l}\text { Overall heat transfer coefficient } \\
\text { (based on the hot-side area) }\end{array}$ & $\mathrm{W} /\left(\mathrm{m}^{2}-{ }^{\circ} \mathrm{C}\right)$ & 2295 \\
\hline SHX flow length & $\mathrm{m}$ & 0.5 \\
\hline SHX total height & $\mathrm{m}$ & 0.97 \\
\hline Total number of plates & - & 386 \\
\hline SHX Volume & $\mathrm{m}^{3}$ & 0.29 \\
\hline Pressure drop on the hot side & $\mathrm{kPa}$ & 13.7 \\
\hline Pressure drop on the cold side & $\mathrm{kPa}$ & 18.3 \\
\hline
\end{tabular}

The temperature distributions inside the heat exchangers are obtained by dividing the IHX and SHX into 100 segments along their flow lengths, as shown in Figures 5 and 6. The temperatures inside the heat exchangers can serve as initial values when starting the transient simulations. 


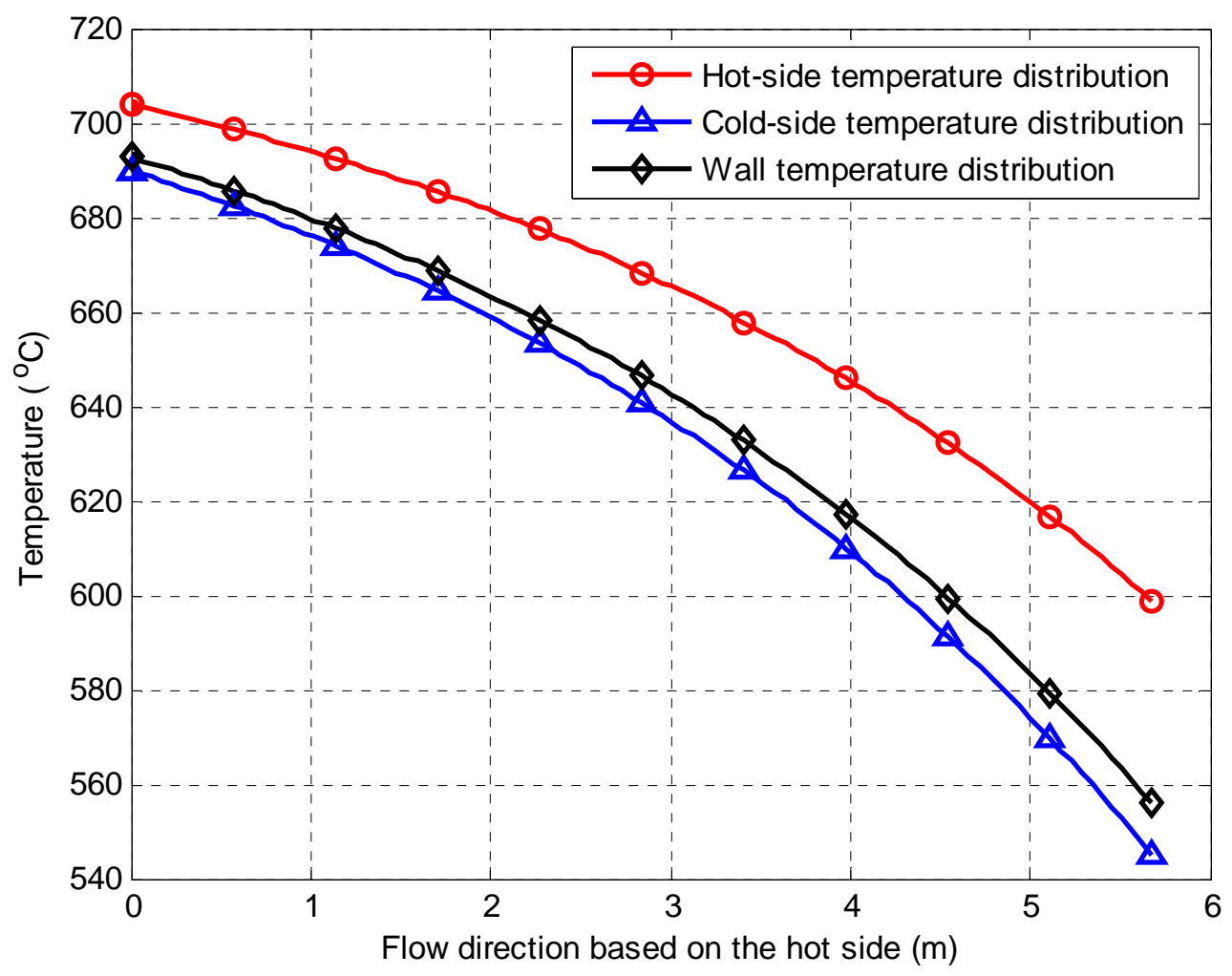

Figure 5. Temperature distribution inside the IHX 


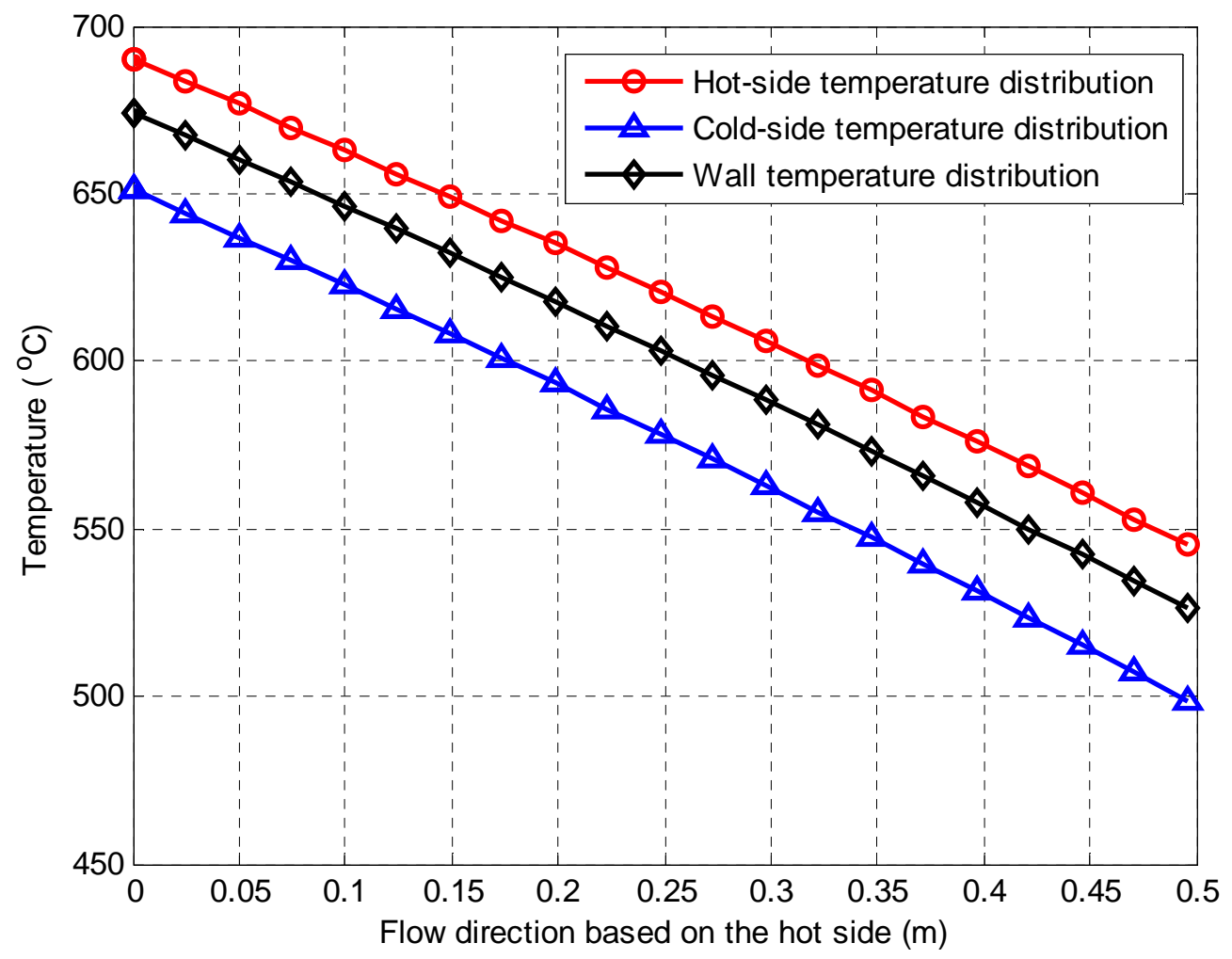

Figure 6. Temperature distribution inside the SHX

\subsection{Reactor Model Verification}

For the one-group point kinetic equation, the analytical solution can be determined [7]. The normalized power $\dot{\mathrm{Q}}_{\text {Nor }}$ can be written as,

$$
\dot{\mathrm{Q}}_{\text {Nor }} \cong\left(\frac{\beta}{\beta-R_{0}}\right) \exp \left(\frac{\lambda R_{0}}{\beta-R_{0}} t\right)-\frac{R_{0}}{\beta-R_{0}} \exp \left(-\frac{\beta-R_{0}}{\Lambda} t\right)
$$

The numerical and analytical results are obtained for both a positive and a negative step reactivity insertion of an amount $\left|R_{0}\right|=0.0025$ into the reactor. In the numerical calculation, the time step is 0.001 second. It can be seen from Figures 7 and 8 , both the numerical and analytical results match well. However, the numerical result for the positive reactivity insertion is smaller than the analytical solution due to the truncation error from large time step in the numerical calculation. 


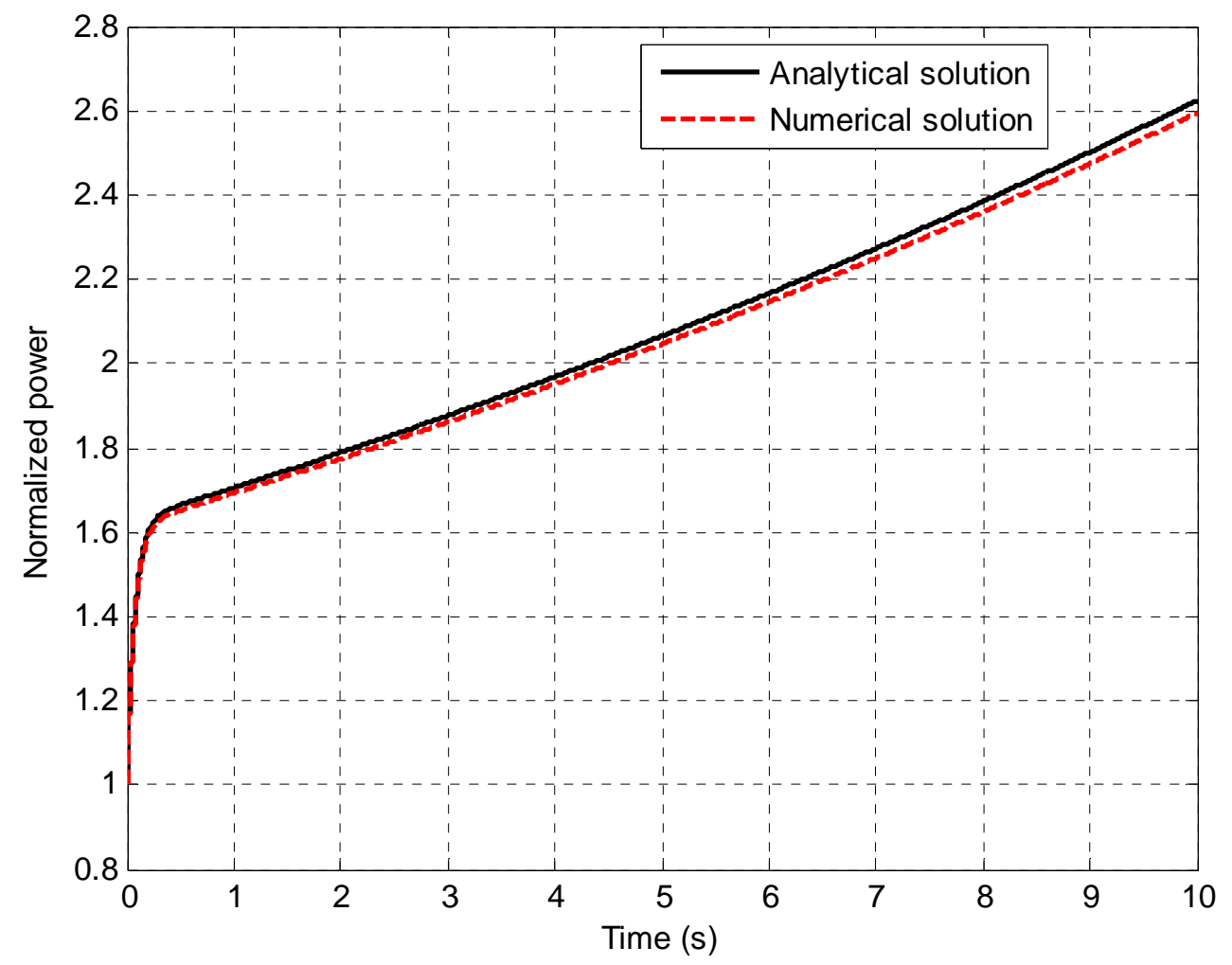

Figure 7. Reactor power level following a positive step reactivity insertion based on analytical and numerical results 


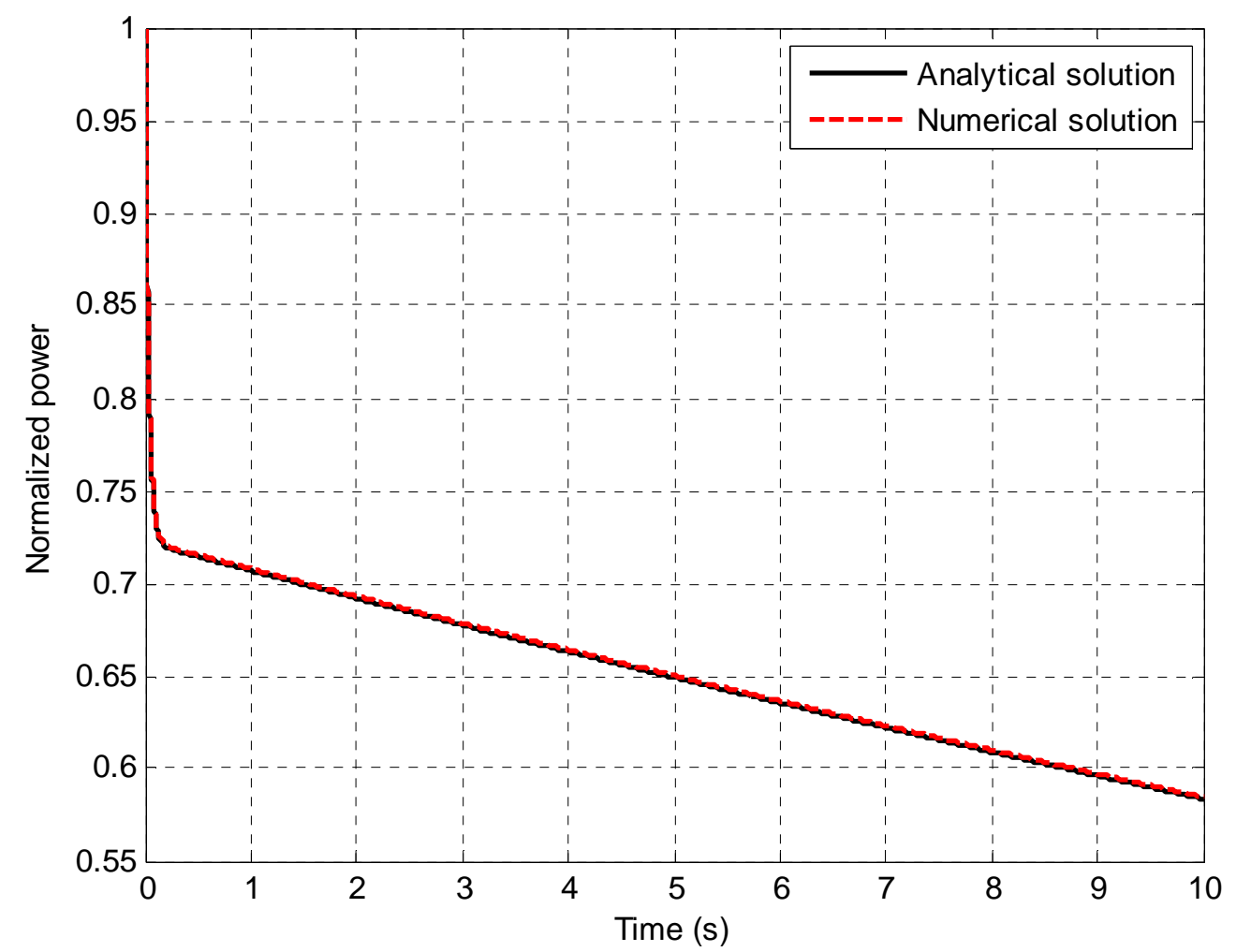

Figure 8. Reactor power level behavior following a negative step reactivity insertion based on analytical and numerical results

\subsection{Heat Exchanger Model Verification}

The dynamic characteristics of a heat exchanger greatly rely on the heat transfer area, fluid flow length, fluid properties and heat transfer rate of the heat exchanger. Since both the IHX and SHX are countercurrent heat exchangers and the models of the two heat exchangers are derived based on similar assumptions that are presented in Second 2, the two-stream heat exchanger models can be verified by using the same method. The dynamic simulator, DYNSIM, has been used in the current study for the verification of the heat exchanger models. A heat exchanger in DYNSIM is divided into a number of sections and then energy balance is applied to each section separately. The model for the heat exchanger that builds in DYNSIM is derived such that the energy balance equations for all sections form a differential-algebraic equations (DAEs) system for dynamic simulations [18]. The dynamic results can be calculated by solving the DAEs simultaneously. For simplicity, a general countercurrent two-stream heat exchanger was adapted and the parameters obtained from the design of the heat exchanger under the nominal steady-state condition were fed into DYNSIM to simulate the dynamic behavior of the heat exchanger. Results comparisons between models used in this paper and the commercial software DYNSIM are performed. It can be seen from Figure 9 that the both heat exchanger models used in this paper and the 
DYNSIM model are depicted the same trends of the dynamic characteristics and the transient results are in good agreement for a temperature transient due to a $10 \%$-step increase in the cold-side inlet mass flow rate starting at 100 seconds.

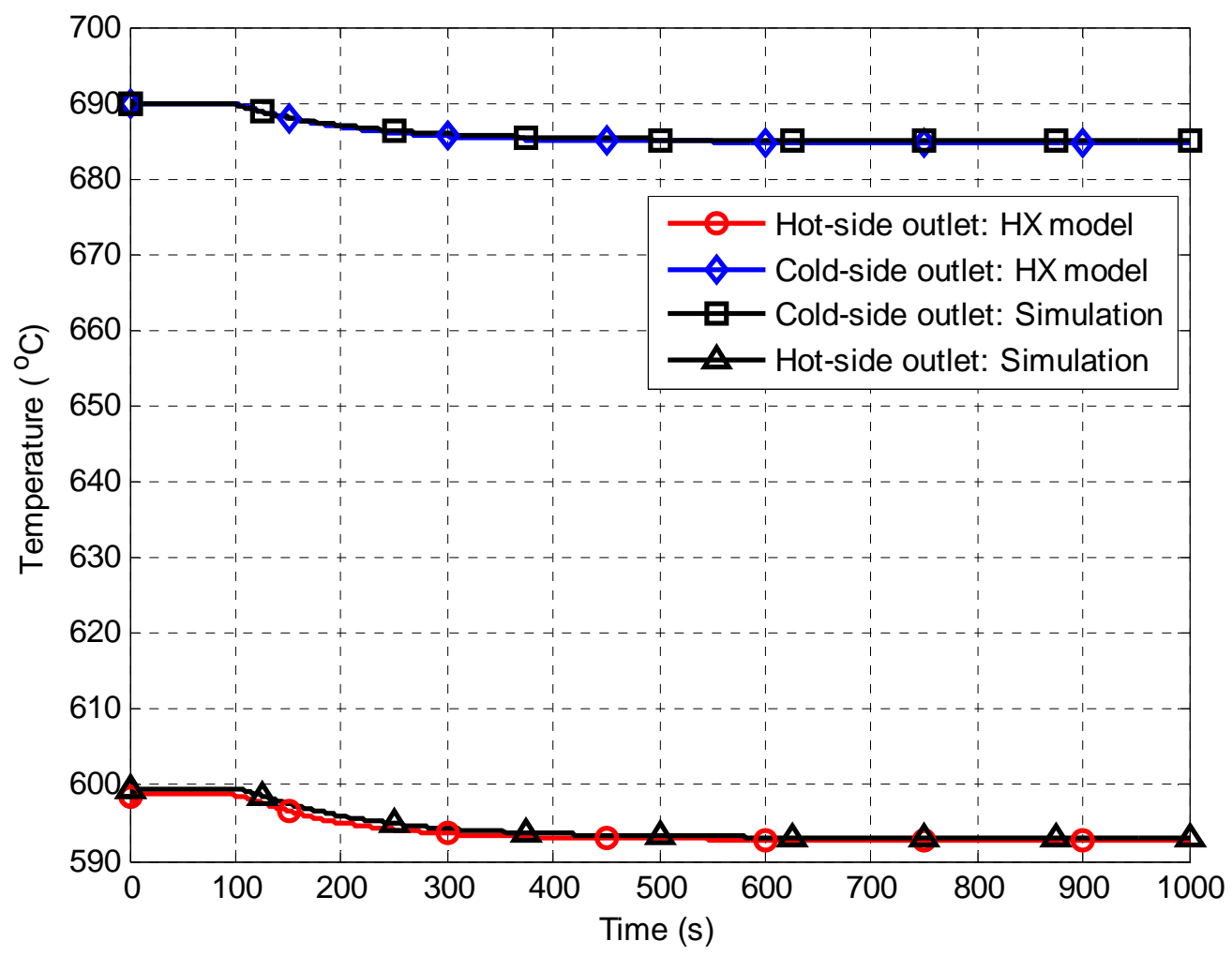

Figure 9. Heat exchanger models verification under flow step change condition

\subsection{Transient Simulations}

As mentioned in Section 1, the FHTR has two identical PCUs in this study. It is assumed that these two loops have identical thermal performance. In our future study, one loop will be connected to a process heat application plant.

The dynamic system model developed in the previous section is tested in this section using three transient scenarios: $1 . \$ 0.05$ reactivity step insertion, $2.50^{\circ} \mathrm{C}$-step increase in the helium inlet temperature on the SHX cold side, and 3. $8 \%$-step increase in the helium mass flow rate on the SHX cold side. It is also assumed that all the control and protection systems in the FHTR will not participate during these transients. The effects of these three transient scenarios are based on the temperatures at different locations in the FHTR system.

The FHTR system nodal structure used in this study is presented in Figure 10. Nodalization sensitivity studies are performed to determine the effective number of nodes used in this dynamic system based on the RIA (Reactivity Insertion Accident) transient. Four different numbers of nodes are used in the mesh sensitivity study. The temperatures at five locations in the FHTR system are 
monitored after the system reaches a steady-state condition following the RIA. It can be seen from Table 5 that all of these four cases present similar results without significant deviations. In this study, the mesh with a total of 948 nodes is selected to simulate the three transient scenarios.

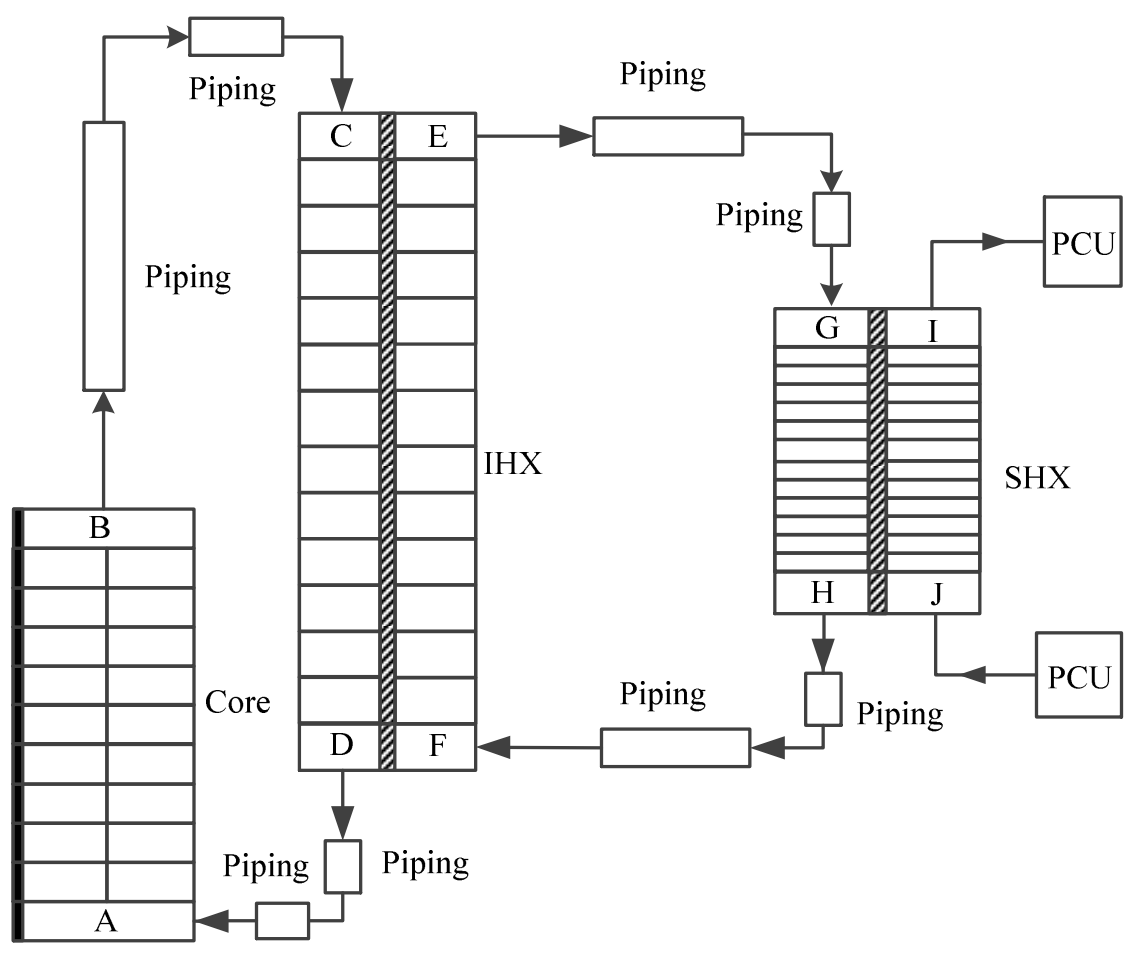

Figure 10. FHTR nodal structure

Table 5. Results of node sensitivity studies*

\begin{tabular}{|c|c|c|c|c|c|c|}
\hline \multirow{4}{*}{ Type } & \multirow{2}{*}{$\begin{array}{c}\text { Total } \\
\text { Number of } \\
\text { Node }\end{array}$} & \multicolumn{5}{|c|}{ Temperature $\left({ }^{\circ} \mathrm{C}\right)$} \\
\cline { 3 - 7 } & $\mathrm{A}$ & $\mathrm{B}$ & $\mathrm{F}$ & $\mathrm{E}$ & $\mathrm{I}$ \\
\hline \multirow{4}{*}{ RIA } & 788 & 601.2 & 711.5 & 548.0 & 559.3 & 658.2 \\
\cline { 2 - 7 } & 948 & 601.9 & 711.1 & 547.8 & 559.3 & 658.3 \\
\cline { 2 - 7 } & 1348 & 602.5 & 710.9 & 547.7 & 559.3 & 658.3 \\
\cline { 2 - 7 } & 1748 & 602.7 & 710.8 & 547.7 & 559.4 & 658.3 \\
\hline
\end{tabular}

: A, B, F, E, \& I refer to the nodes shown in Figure 10

\subsection{5\$ reactivity step insertion}

A positive reactivity insertion could be caused by lifting a control rod or control rod ejection. The insertion of a positive reactivity causes an increase of the reactor power, which leads to temperature increases in the fuel and primary coolant. The negative 
temperature feedback brings a negative reactivity into the core, resulting in a power decrease and therefore a temperature decrease in the fuel to compensate for the temperature increase in the core. In this exercise, a positive reactivity of $0.05 \$$ is inserted into the core at 100 seconds after the reactor operates under its full nominal power condition. Figure 11 shows the reactor power evolution before and after the reactivity insertion. The reactor reaches the maximum power at about 190 seconds, and then starts to decrease. After about 770 seconds, the reactor power reaches a stable value with approximately $1 \mathrm{MW}$ additional power. Figure 12 shows the temperature transients after the reactivity insertion. The temperature of the primary coolant at the core outlet increases after the reactivity insertion. Temperatures at the IHX hot-side inlet and cold-side outlet increase fairly quickly, while the temperatures at the SHX both sides have a time delay in responding, starting to increase around 240 seconds. This is because the piping distance between the IHX and SHX introduces a time delay into the system. Therefore, the delay time can be estimated by dividing the flow length by the flow velocity.

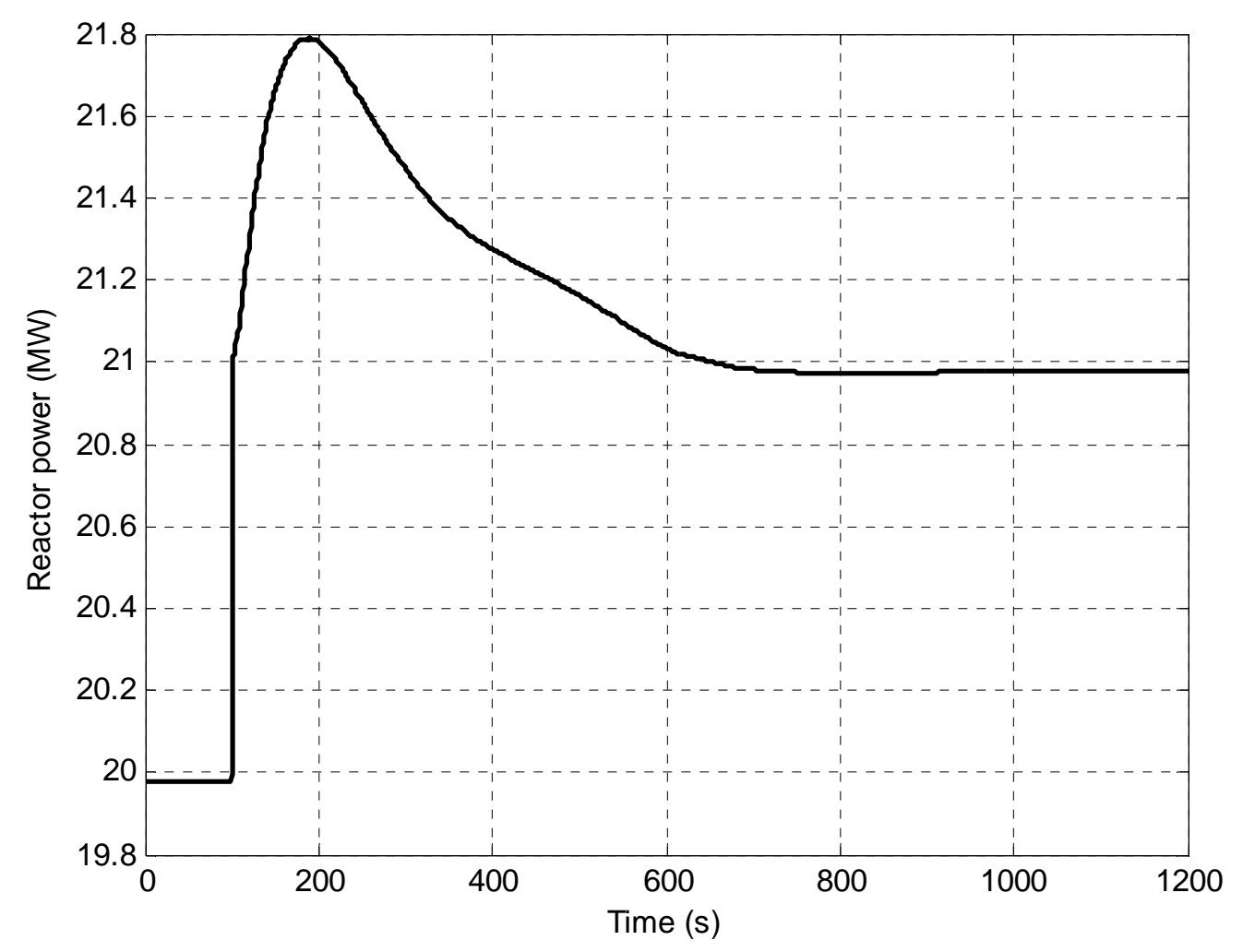

Figure 11. Reactor power variation after the $0.05 \$$ reactivity insertion 


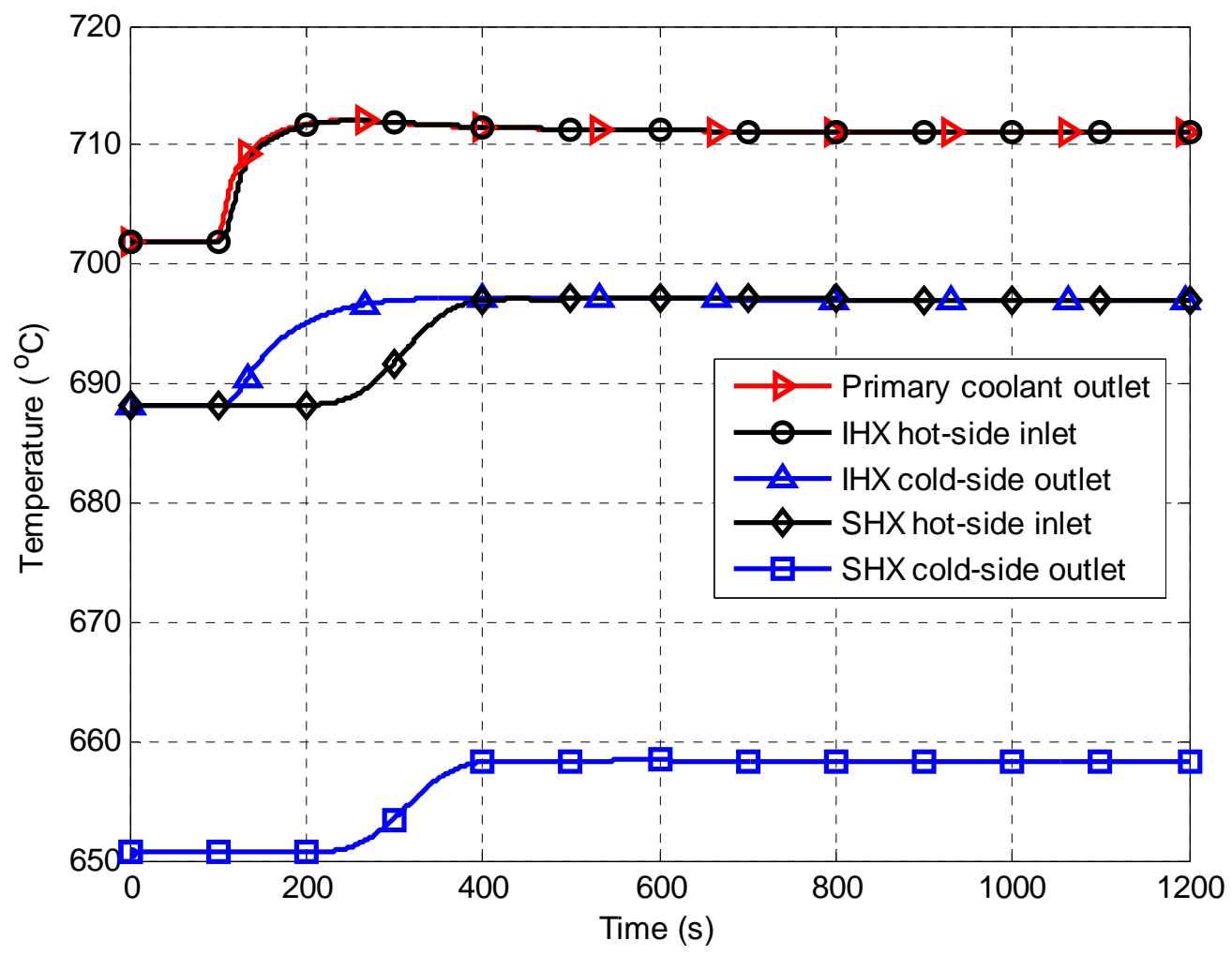

Figure 12. Fluid temperature variations after the reactivity insertion

\subsection{2 $50^{\circ} \mathrm{C}$-step increase in the helium inlet temperature on the $\mathrm{SHX}$ cold side}

A step increase of the helium inlet temperature on the SHX cold side at 100 seconds after the system reaches its nominal steadystate condition is initiated. The increase of the helium inlet temperature causes the salt temperatures in the intermediate loop to increase, as shown in Figures 13 and 14. The connecting pipe between the IHX and SHX leads to a delayed transient response from 100 to about 240 seconds. The reactor does not receive any disturbances within this time delay. The temperature increase in the intermediate loop is propagated to the reactor primary loop, increasing the reactor core inlet temperature. The primary coolant temperature rises by about $22{ }^{\circ} \mathrm{C}$ at the hot side of the IHX. The increasing inlet temperature raises the average temperatures of the fuel and primary coolant in the reactor core. Due to the negative feedback of the fuel and primary coolant, the power decreases because negative reactivity is introduced into the core. It can be seen from Figure 15 that the nuclear reactor core responds to the increased fuel and coolant temperatures by decreasing its power and the primary coolant outlet temperature actually drops, as shown in Figure 13, because of the lower power in the core. Vice versa, a positive feedback is then introduced into the core, leading to a small increase of reactor power from 540 to 1000 seconds. It can be seen from Figure 15 that the reactor power finally reaches a stable 
value with approximately a 5-MW power decrease due to the temperature step increase in helium at the SHX cold-side inlet. The decreasing inlet temperature on the hot side of the IHX and the increased outlet temperature on the hot side of the SHX lead to temperature oscillations on the cold side inlet temperature of the IHX, as shown in Figure 14.

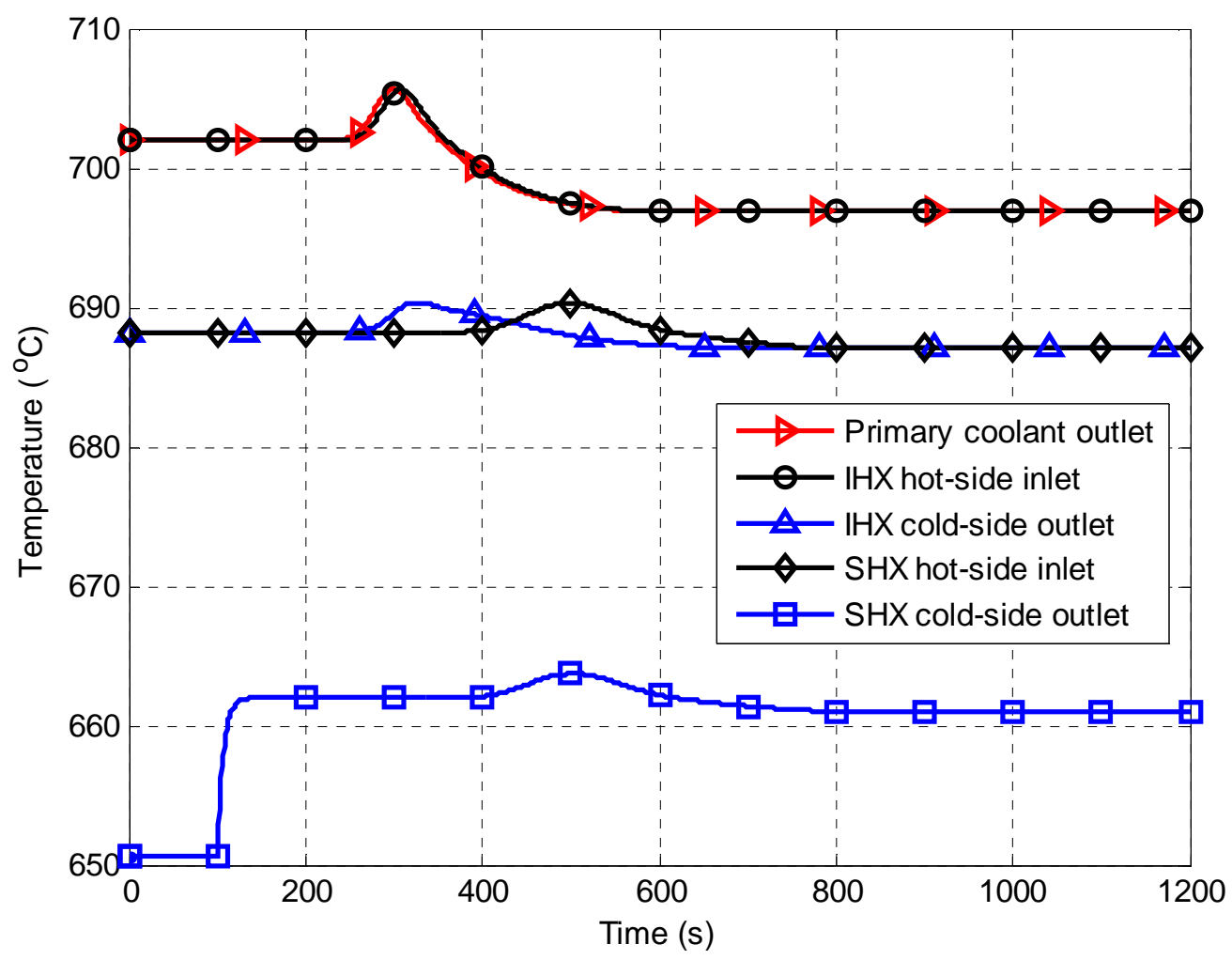

Figure 13. Temperature variations after a $10^{\circ} \mathrm{C}$-step increase for the helium inlet temperature on the SHX cold side 


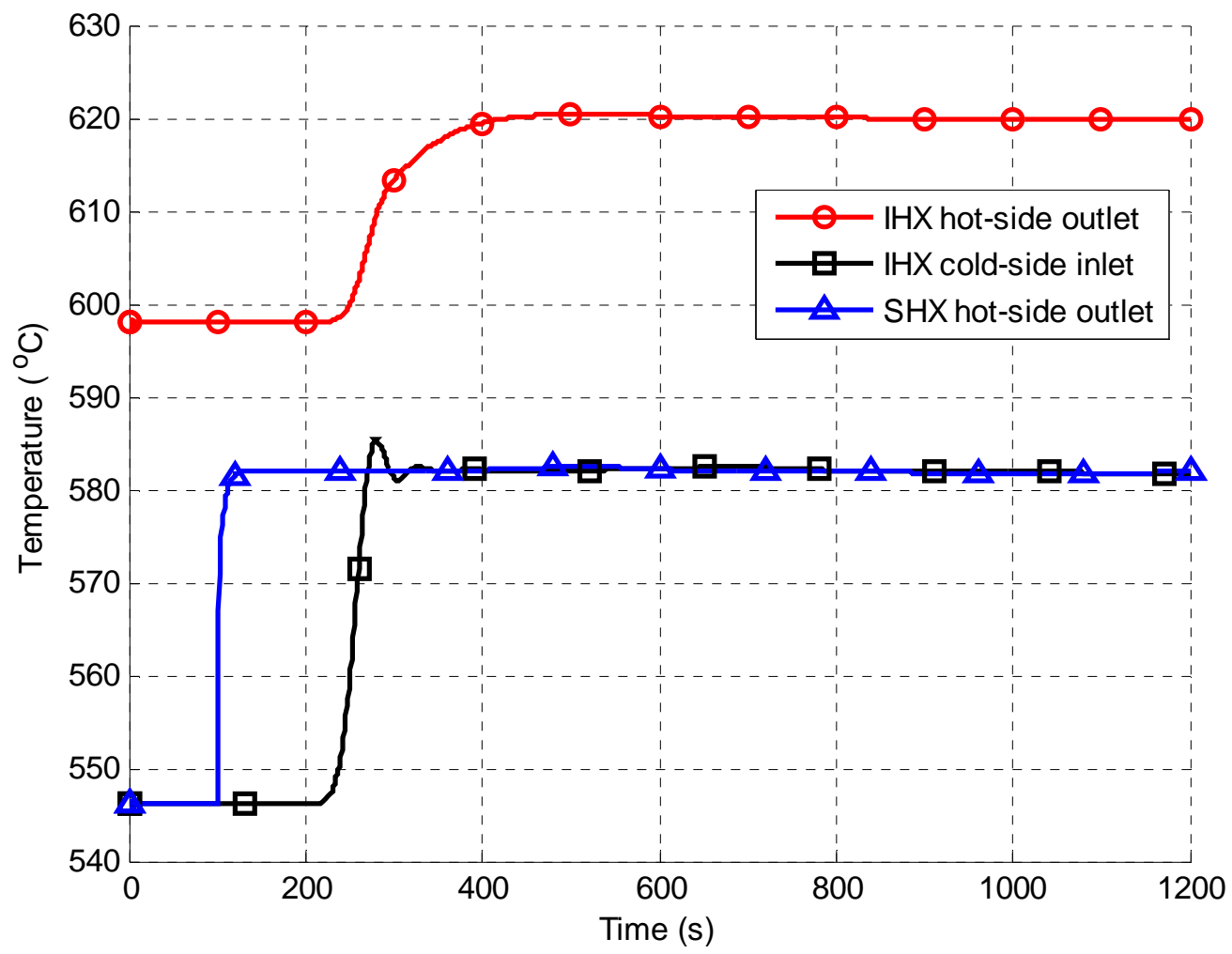

Figure 14. Temperature variations after a $10^{\circ} \mathrm{C}$-step increase for the helium inlet temperature on the SHX cold side 


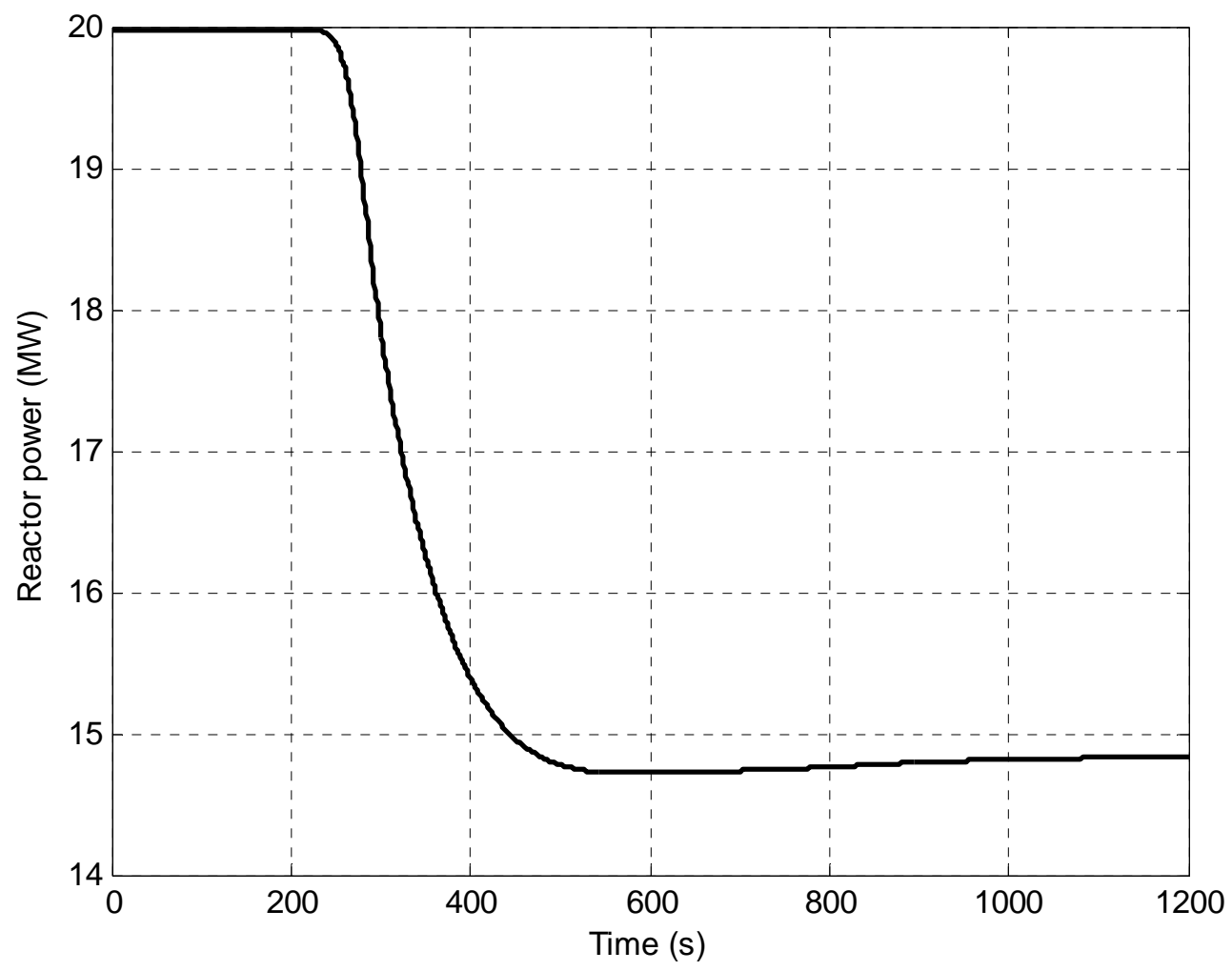

Figure 15. Reactor power variation after a temperature step increase for helium at the SHX inlet

\subsubsection{8\% helium mass flow rate step increase on the SHX cold side}

When the PCU operates at its nominal condition, the helium mass flow rate is kept at a constant value. Figures 16 and 17 depict the temperature variations at different locations in the FHTR following an 8\%-helium mass flow rate step increase after 100-second nominal steady-state operation. The increase of the helium mass flow rate causes a reduction in the outlet temperature on the helium side. The initiating event at the inlet of the SHX cold side quickly propagates to the cold-side outlet and the hot-side outlet locations because of the high helium velocity and small helium traveling distance. The connecting pipe between the IHX and SHX introduces a delayed transient response from 100 to about 240 seconds. It can be seen from Figure 18 that the reactor power experiences a rapid increase starting at 240 seconds because a positive reactivity is introduced into the reactor core by the negative temperature feedback from the fuel and primary coolant. 


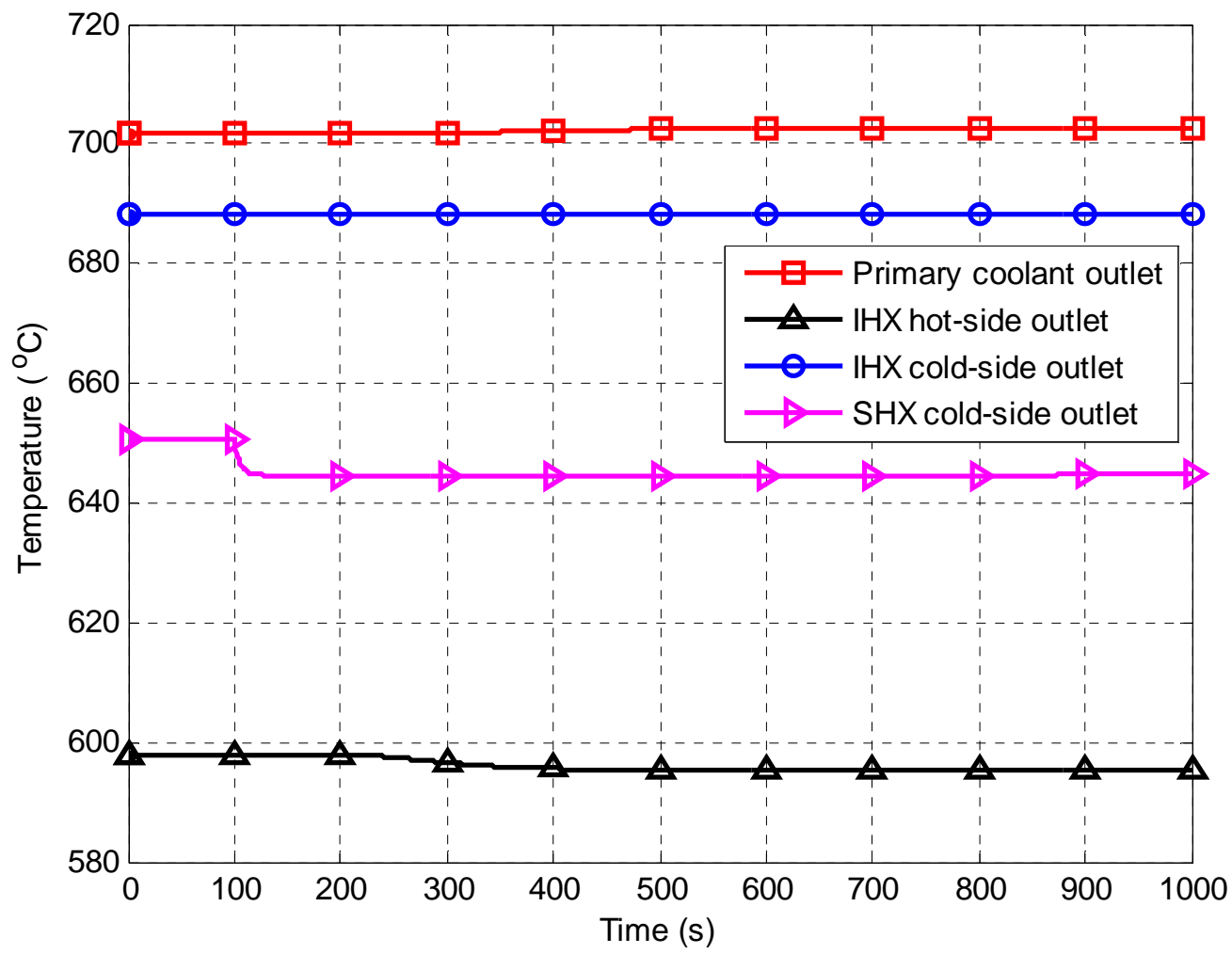

Figure 16. Temperature evolutions at different locations following an $8 \%$-helium mass flow rate step increase 


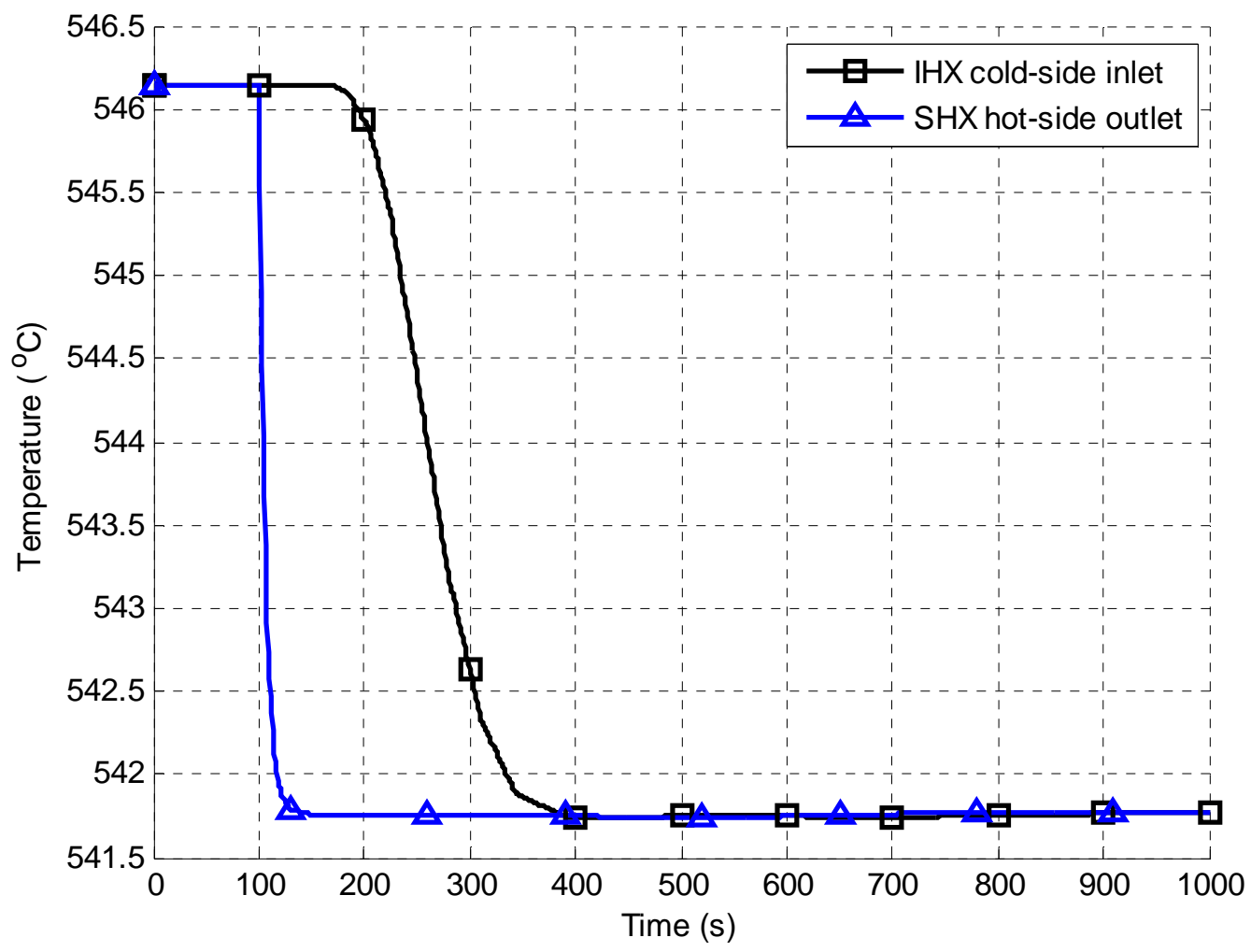

Figure 17. Temperature evolutions at different locations following an $8 \%$-helium mass flow rate step increase 


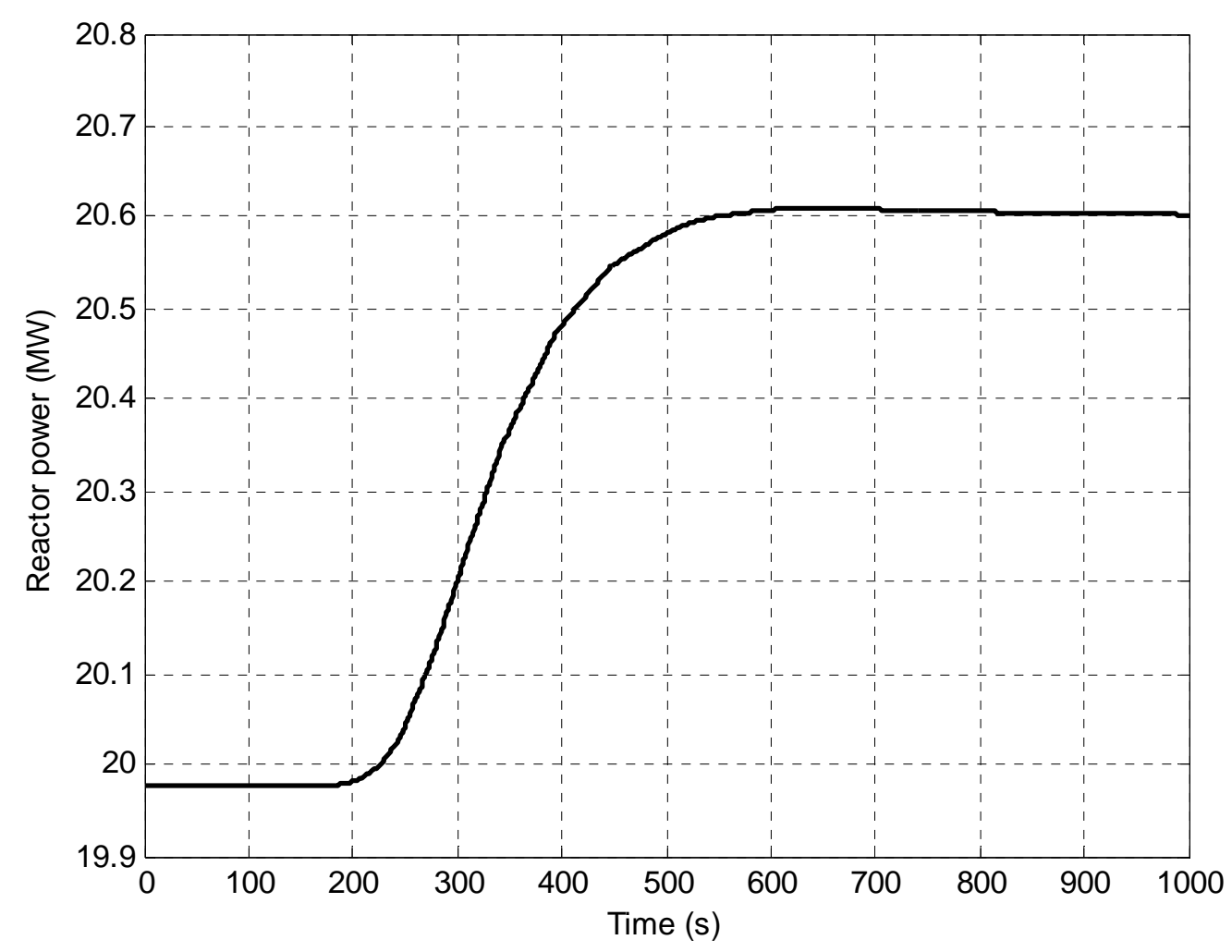

Figure 18. Reactor power following the helium flow rate change

\section{Conclusions}

The preliminary design of the IHX and SHX for a two-loop, 20-MW ${ }_{\text {th }}$ FHTR with a helium Brayton power cycle has been proposed based on a thermal hydraulic analysis. The geometric parameters of each component under the nominal operation are obtained via steady-state calculations. These parameters have been fed into dynamic models to be implemented into an integral system dynamic code. The reactor and heat exchangers models are compared with the theoretical solutions and results obtained from the commercial software, respectively. The models will be validated using the experimental data to be obtained at The Ohio State University in the near future. The simulation results of three initiating events, a positive reactivity insertion, a step increase of helium flow rate, and a step increase of helium inlet temperature to the SHX in the PCU are obtained. The results demonstrate that the reactor, for the three transient scenarios analyzed, has inherent safety features. The increase of the temperatures of the pebble fuel and primary coolant is mitigated by the decrease of the reactor power due to the negative temperature feedbacks. The results also indicate the intermediate loop consisting of the IHX and SHX plays a significant role in the transient progression of the integral system. The traveling distance between the IHX and SHX for the intermediate working fluid gives some extra time for the control system to respond to the initiating events from the PCU side. More transient scenarios will be investigated, including a loss-of-coolant-accident 
and those due to failure in the PCU and/or process heat application plants, to better understand the integral behaviors of the coupled reactor, power conversion system, and process heat application plants.

\section{Acknowledgements}

The authors would like to acknowledge the support to this project by the U.S. Department of Energy Nuclear Energy University Programs (NEUP). The assistances provided by Mr. Qiuping Lv of the Ohio State University and Mr. Isaac Skavdahl of University of Idaho are appreciated.

\section{Nomenclature}

$A$

$A_{c}$

$A_{P}$

$A_{f}$

$A_{R}$

C

$c h$

$c_{p}$

$d_{p}$

$D_{\text {FTHX }}$

$D_{o}$

$D_{\text {OSF }}$

$D_{v o}$

$e^{*}, p^{*}, r^{*}$

F

$f_{f}$ total heat transfer area in one segment of the IHX $\left[\mathrm{m}^{2}\right]$

cross-sectional area of the reactor core $\left[\mathrm{m}^{2}\right]$

plate surface area that is in contact with the surrounding fluid in the OSF $\left[\mathrm{m}^{2}\right]$

fin surface area that is in contact with the surrounding fluid in the OSF $\left[\mathrm{m}^{2}\right]$

total heat transfer area in one computational segment in the reactor core $\left[\mathrm{m}^{2}\right]$

concentration of neutron precursor

fin height $[\mathrm{m}]$

specific heat $\left[\mathrm{J} /\left(\mathrm{kg}^{-}{ }^{\circ} \mathrm{C}\right)\right]$

pebble outer diameter $[\mathrm{m}]$

hydraulic diameter of the FTHX [m]

inner diameter of the outer plain tube $[\mathrm{m}]$

hydraulic diameter of the OSF [m]

volume-based fluted tube outer diameter [m]

dimensionless geometric parameters in Eqs. (9-11)

negative feedback coefficient

friction factor 
heat transfer coefficient $\left[\mathrm{W} /\left(\mathrm{m}^{2}-{ }^{\circ} \mathrm{C}\right)\right]$

Colburn factor

thermal conductivity $\left[\mathrm{W} /\left(\mathrm{m}-{ }^{\circ} \mathrm{C}\right)\right]$

fin length of the OSF [m]

$L$ height of activity region of the reactor core [m]

$m_{f}$ primary coolant mass in one node $[\mathrm{kg}]$

$\dot{m}$

coolant mass flow rate $[\mathrm{kg} / \mathrm{s}]$

$n$

neutron density $\left[\mathrm{n} / \mathrm{m}^{3}\right]$

$\mathrm{Nu} \quad$ Nusselt number

$P_{x} \quad$ pitch in the span-wise direction [m]

$P_{y} \quad$ pitch in the stream-wise direction [m]

$\operatorname{Pr} \quad$ Prandtl number

$\dot{q}_{n}{ }^{\prime \prime} \quad$ internal fission power density $\left[\mathrm{W} / \mathrm{m}^{3}\right]$

$\dot{q}_{c} \quad$ heat transfer rate via convective heat transfer [W]

$\dot{\mathrm{Q}}_{\text {Nor }} \quad$ normalized power

$R_{C R} \quad$ control rod reactivity

$R_{0} \quad$ initial reactivity

Re Reynolds number

$t \quad$ time $[\mathrm{s}]$

$t_{P} \quad$ fin thickness $[\mathrm{m}]$

T temperature $\left[{ }^{\circ} \mathrm{C}\right]$

$\bar{T} \quad$ mass weighted temperature in the core $\left[{ }^{\circ} \mathrm{C}\right]$

$\bar{T}(0) \quad$ core reference temperature $\left[{ }^{\circ} \mathrm{C}\right]$

flow velocity in the $\mathrm{SHX}[\mathrm{m} / \mathrm{s}]$

flow velocity in the IHX $[\mathrm{m} / \mathrm{s}]$

V 
flow length for an individual mesh volume of the SHX [m]

\section{Greek symbols}

$\alpha$

surface area density $\left[\mathrm{m}^{2} / \mathrm{m}^{3}\right]$

$\beta$

delayed neutron fraction

$\varepsilon$

volume fraction in pebble bed

$\eta_{f}$

fin efficiency

$\theta^{*}$

dimensionless geometric parameter in Eqs. (9-11)

$\lambda$

decay constant $\left[\mathrm{s}^{-1}\right]$

$\Lambda$

mean neutron generation time [s]

$\mu$

dynamic viscosity $[\mathrm{kg} / \mathrm{m}-\mathrm{s}]$

$\rho$

density $\left[\mathrm{kg} / \mathrm{m}^{3}\right]$

$\phi$

fin parameter

$\chi, \delta, \gamma$

dimensionless geometric parameters in Eq. (17)

\section{Subscripts}

$c$

cold side of the SHX

$f$

coolant

$h$

hot side of the SHX

pb pebble fuel

$P$

plate in the SHX

shell side of the IHX

$t$

tube side of the IHX

W

tube wall of the IHX

\section{Superscripts}

in inlet of a specific control volume 
out

outlet of a specific control volume

$\begin{array}{ll}\text { Acronyms and abbreviations } \\ \text { DHX } & \text { DRACS heat exchanger } \\ \text { DRACS } & \text { direct reactor auxiliary cooling system } \\ \text { FHR } & \text { fluoride salt-cooled high-temperature reactor } \\ \text { FHTR } & \text { fluoride salt-cooled high-temperature rest reactor } \\ \text { FTHX } & \text { fluted tube heat exchanger } \\ \text { IHX } & \text { intermediate heat exchanger } \\ \text { LMTD } & \text { log-mean temperature difference } \\ \text { MSR } & \text { molten salt reactor } \\ \text { NDHX } & \text { natural draft heat exchanger } \\ \text { OSF } & \text { offset strip-fin heat exchanger } \\ \text { PB-AHTR } & \text { pebble bed advanced high-temperature reactor } \\ \text { PCU } & \text { power conversion unit } \\ \text { RIA } & \text { reactivity insertion accident } \\ \text { SHX } & \end{array}$

\section{References}

[1] Forsberg, C.W., “The Advanced High-Temperature Reactor: High-Temperature Fuel, Liquid Salt Coolant, and Liquid-MetalReactor Plant," Progress in Nuclear Energy, 47(1-4), pp. 32-43, 2005.

[2] MIT, UW Madison, and UC Berkeley Facilitators, "Fluoride-Salt-Cooled, High-Temperature Reactor (FHR) Development Roadmap and Test Reactor Performance Requirements White Paper,” Massachusetts Institute of Technology: UCBTH-12-004, 2013.

[3] Wang, X., Lv, Q., Sun, X., Christensen, R.N., Blue, T.E., Yoder, G., Wilson, D., and Sabharwall, P., “A Modular Design of a Direct Reactor Auxiliary Cooling System for AHTRs," Transactions of the American Nuclear Society, 104, pp. 1077-1080, 2011.

[4] Zwaan, S.J., Boer, B., Lathouwers, D., and Kloosterman, J.L., "Static Design of a Liquid-Salt-cooled Pebble Bed Reactor (LSPBR)," Annals of Nuclear Energy, 34, pp. 83-92, 2007.

[5] Galvez, C., "Design and Transient Analysis of Passive Safety Cooling Systems for Advanced Nuclear Reactors," UC Berkeley: Ph.D. Dissertation, 2011. 
[6] Wakao, N. and Kaguei, S., "Heat and Mass Transfer in Packed Beds," Gordon and Breach Science Publishers, New York, NY, 364, 1982.

[7] Duderstadt, J.J. and Hamilton, L.J., “Nuclear Reactor Analysis,” John Wiley \& Sons, Inc, 1976.

[8] Qualls, A.L., Cetiner, M.S., and Wilson, T.L., “Advanced High-Temperature Reactor Dynamic System Model Development,” ORNL/TM-2012/174, 2012.

[9] Dhahran, S.A., "Design and Operate a Fouling Monitoring Device to Study Fouling at Twisted Tube," King Fahd University of Petroleum \& Minerals: M.S. Thesis, 2007.

[10] Garimella, S. and Christensen, R.N., "Heat Transfer and Pressure Drop Characteristics of Spirally Fluted Annuli: Part I: Hydrodynamics," Journal of Heat Transfer, 117(1), pp. 54-60, 1995.

[11] Garimella, S. and Christensen, R.N., "Heat Transfer and Pressure Drop Characteristics of Spirally Fluted Annuli: Part II: Heat Transfer," Journal of Heat Transfer, 117(1), pp. 61-68, 1995.

[12] Garimella, S., "Experimental Investigation of Heat Transfer and Pressure Drop Characteristics of Annuli with Spirally-fluted Inner Tubes," The Ohio State University: Ph.D. Dissertation, 1990.

[13] Urquiza, E., "Transient Thermal, Hydraulic, and Mechanical Analysis of a Counter Flow Offset Strip Fin Intermediate Heat Exchanger using an Effective Porous Media Approach,” UC Berkeley: Ph.D. Dissertation, 2009.

[14] Losier, C.R.D., Subramanian, S., Ponyavin, V., Chen, Y., Hechanova, A.E., and Peterson, P.F., "The Parametric Study of an Innovative Offset Strip-Fin Heat Exchanger,” Journal of Heat Transfer, 129, pp. 1453-1458, 2007.

[15] Chen, M., Kim, I., Sun, X., Christensen, R., Bartel, N., Utgikar, V., and Sabharwall, P., "Dynamic Response Analysis of a Scaled-Down Offset Strip-Fin Intermediate Heat Exchanger,” Transactions of American Nuclear Society, 109, pp. 270-273, 2013.

[16] Manglik, R.M. and Bergles, A.E., "Heat Transfer and Pressure Drop Correlations for the Rectangular Offset Strip Fin Compact Heat Exchanger,” Experimental Thermal Fluid Science, 10, pp. 171 - 180, 1995.

[17] Sabharwall, P., Kim, E.S., McKellar, M., and Anderson, N., "Process Heat Exchanger Options for Fluoride Salt High Temperature Reactor," INL/EXT-11-21584, 2011.

[18] Gani, R., Sorensen, E., and Perregaard, J., "Design and Analysis of Chemical Processes through DYNSIM,” Industrial \& Engineering Chemistry Research, 31, pp. 244-254, 1992. 